\title{
HACIENDA LOCAL Y REDES FINANCIERAS EN LA CATALUÑA BAJOMEDIEVAL: LOS TESOREROS DEL MUNICIPIO DE GERONA (1355-1443) ${ }^{1}$
}

\author{
MUNICIPAL TREASURY AND FINANCIAL NETWORKS IN LATE MEDIEVAL CATALONIA: \\ THE TREASURERS OF GERONA CITY COUNCIL (1355-1443)
}

\author{
Albert Reixach Sala \\ Institución Milá y Fontanals (CSIC)
}

Resumen: El presente artículo pretende analizar la figura del clavari de les imposicions de la ciudad de Gerona, tesorero principal y oficio fundamental de la administración municipal que cristalizó, igual que en la mayoría de poblaciones catalanes, durante la segunda mitad del siglo XIV. Se presta especial atención a la treintena de individuos que ocuparon dicho cargo entre 1355 y 1443 . Así se aportan datos prosopográficos sobre sus actividades profesionales, extracción social, trayectorias y relaciones, a fin de interpretar mejor las instituciones locales.

Palabras clave: Hacienda municipal, Cataluña bajomedieval, redes financieras; política local.

\begin{abstract}
This essay aims to analyze the office called clavari de les imposicions in the city of Girona, the most important local treasurer and a crucial position within the municipal administration that cristalyzed, like in most Catalan towns, during the second half of the 14th c. Major attention is devoted to the group of around thirty individuals that occupied this office between 1355 and 1443. In so doing, it provides prosopographical data about their professional activities, social background, careers and relationships, as a means to better interpret local institutions.

Keywords: Municipal treasury, Late Medieval Catalonia, financial networks, local politics.
\end{abstract}

1 Este trabajo se ha realizado en el marco del proyecto «Financieros al servicio del poder en la Corona de Aragón (s. XIV-XV): Métodos, agentes, redes (ref. HAR2011-24839» financiado por el Ministerio de Innovación y Ciencia y, asimismo, en el seno del grupo de investigación consolidado «Renda feudal 


\section{Introducción}

El primer día del año 1364, reunido en el convento de franciscanos, el consejo general de la ciudad de Gerona, cuyos miembros acababan de ser elegidos, resolvía que el cambista Ramon Medir se ocupara (él y nadie más que él) de percibir el arriendo de impuestos indirectos bajo control del municipio para pagar las rentas emitidas por la universitas y de no destinar dichas cantidades a ningún otro fin. Sobre todo en esto último insistían las instrucciones que tenía que seguir el tesorero municipal de reciente creación y que pronto sería conocido como clavari de les imposicions. ${ }^{2}$

El presente trabajo se propone, precisamente, analizar la figura del clavari de les imposicions de la ciudad de Gerona, oficio por excelencia de una administración financiera que cristalizó, como en la mayoría de municipios catalanes, en las décadas de 1360 y 1370. Asimismo, el estudio de los individuos que ocuparon dicho cargo de clavari entre 1355 y 1443 ha de permitirnos realizar una primera aproximación a una prosopografía de mayor alcance acerca de los sujetos que articularon el arca común del municipio gerundense con las redes financieras de la época. ${ }^{3}$

Para todo ello nos basaremos en un vaciado exhaustivo de las ricas series del archivo municipal de Gerona conservadas para el periodo analizado y que incluyen libros de actas, correspondencia, registros notariales elaborados por el escribano del consejo y libros de cuentas. ${ }^{4}$ Además, completaremos la mayor parte de datos biográficos con la información que nos ofrecen los también nutridos fondos de los distintos notarios que actuaron simultáneamente para clientela privada en la notaría real de la ciudad.

i fiscalitat a la Catalunya baixmedieval» (2009 SGR 1367) del Comissionat per a Universitats i Recerca de la Generalidad de Cataluña. Abreviaturas utilizadas: ACA = Archivo de la Corona de Aragón, $\mathrm{C}=$ Cancillería $; \mathrm{G}=$ serie dicha $\mathrm{G}$ dentro del fondo Generalitat; $\mathrm{AHG}, \mathrm{Gi}-0 \mathrm{X}$ = Arxiu Històric de Girona, Fonts notarials, Notaria de Girona-0X; AMGi = Arxiu Municipal de Girona, Fons Ajuntament de Girona; I.1.1.= serie Manuals d'acords; I.1.2.1.= serie Ordinacions dels jurats/Correspondència; I.2.1. = serie Plec de condicions; I.2.2. = serie Botiga del forment; I.3.3.1.1.= serie Llibres d'àpoques; I.3.3.1.2. = serie Llibres de comptes del clavari; I.3.3.1.5. = serie Comptes de l'administració municipal; I.3.3.2.4 =Llibres de censals $i$ violaris; VIII.1.1. = serie Talles; 1lig.= legajo. Las cantidades monetarias se expresan en libras o sueldos barceloneses (l.b., s.b) o florines de oro de Aragón (fl.).

2 AMGi, I.3.3.1.1., llig. 1, reg. 1, ff. 64r-v, 1364/01/01.

3 Cabe señalar, de entrada, que este trabajo forma parte de una tesis doctoral actualmente en proceso de revisión. Esta circunstancia, sumada a las comprensibles limitaciones de espacio de la presente publicación, implica el hecho de que algunos aspectos relativos a la institución municipal o a su evolución sean sólo apuntados a la espera de poder desarrollarlos con mayor detalle en futuros trabajos. 


\section{La aparición de la clavaria de les imposicions en el proceso de consolidación de la hacienda local (1350-1360)}

Antes de entrar a analizar los rasgos principales del cargo de clavari de les imposicions y el perfil de los individuos que lo ocuparon, veamos brevemente cuándo y cómo apareció la administración que regía en un contexto histórico preciso y adaptándose a las novedades financieras e institucionales. Uno de los elementos fundamentales de este proceso fue, sin lugar a dudas, el endeudamiento de la universitat de Gerona, que contribuyó decisivamente a consolidar la hacienda local como en muchos otros lugares del principado. En efecto, en paralelo al afianzamiento definitivo del sistema fiscal municipal, nacía un cargo destinado a gestionar el pilar central de dicho sistema, esto es el pago de la deuda pública a largo plazo, que se asentó de manera irreversible en las finanzas locales tras los cuantiosos subsidios otorgados al rey durante la Guerra de los dos Pedros (1356-69). ${ }^{5}$

De hecho, la cristalización de esta nueva tesorería específica alrededor de 1360 culminaba un proceso iniciado en la década de 1340. Entonces, ante las crecientes demandas fiscales de la Corona, las primeras emisiones de rentas vitalicias y perpetuas (violaris y censals) y la prolongación de los periodos de recaudo de impuestos indirectos a cargo de las administración municipal, los regidores empezaron a nombrar a vecinos ajenos al ejecutivo para que se ocuparan de forma temporal de la gestión de los ingresos que generaba la venta temporal de las imposiciones, con los que se debía hacer frente a la deuda. ${ }^{6} \mathrm{De}$ todos modos, entre aproximadamente 1355 y 1385, con el recurso casi sistemático ante la mayoría de necesidades a la emisión de rentas consignadas al conjunto de impuestos indirectos, el clavari de les imposicions se convertiría definitivamente en un cargo de nombramiento anual y la clavaria de les imposicions en una verdadera institución. ${ }^{?}$

5 Sobre las dinámicas que condujeron a la cristalización de los sistemas fiscales municipales: Sánchez \& Orti, 1997a: 233-278; Orti, 2006: 275-316. Un balance de dicho proceso en los distintos territorios de la Corona de Aragón: Sánchez, Furió \& Sesma, 2008: 99-130. A propósito del endeudamiento de las haciendas municipales catalanas, véase el conjunto de estudios reunidos (y toda la bibliografía que incluyen) en Sánchez, 2009. Un estado de la cuestión acerca de los municipios del reino de Aragón: Abella, 2009: 47-64.

6 Así, en 1342, un año antes de las primeras ventas de rentas, los jurats designaron para esta tarea dos mercaderes locales: AMGi, I.1.2.1., 1lig. 4, reg. 2, f. 116r, 1342/01/01.

7 Podemos considerar el ejercicio de 1355 como el inicio del proceso de cristalización de la clavaria de les imposicions en Gerona porque fue la primera ocasión en la que documentamos que se auditaron 
Este nuevo tesorero era llamado así porque justamente le fue asignado el producto del arriendo anual por parte del gobierno municipal de los impuestos indirectos aplicados sobre el consumo y la circulación de productos y mercancías (imposiciones o sisas) y que debían destinarse a la satisfacción de los intereses y, hasta donde fuera posible, a la amortización de las rentas vitalicias o perpetuas (violaris y censals) emitidas por el conjunto de la comunidad ciudadana. En el caso de Gerona, además, el nuevo clavari se escindía de una tesorería municipal preexistente, controlada por uno de los seis regidores (jurats) que se intitulaba tenedor de las cuentas de este órgano de magistrados locales y que, en adelante, pasaría a denominarse clavari dels jurats. ${ }^{8}$

Con el establecimiento del clavari de les imposicions, tuvo lugar cierta reestructuración de la hacienda municipal que, evidentemente, entrañaba un sistema más complejo de cajas y administraciones allende el arriendo de impuestos indirectos y el pago de la deuda. A lo largo de todo el periodo entre aproximadamente 1355 y 1445 hubo necesidades de moneda por motivos muy diversos: desde demandas fiscales ligadas a la guerra hasta la obligación de mejorar el

por separado unas cuentas de los ingresos devengados exclusivamente por el arriendo de las imposiciones por parte de los regidores de las de los emolumentos generales de la administración municipal: AMGi, I.1.1., n.2, f. 155v-157v, 1356/11/17. Esta novedad local probablemente estaba vinculada a transformaciones de mayor alcance en la gestión de las ayudas fiscales pactadas entre el estamento real y la monarquía a propósito de expediciones marítimas para el control de la isla de Cerdeña. En pocas palabras, en el donativo aprobado en el Parlamento de Vilafranca del Penedès de 1353 se estipuló por primera vez de manera clara que las autoridades municipales podían retenerse una parte de lo recaudado mediante impuestos indirectos para que pagaran directamente los intereses de la deuda emitida con el fin de financiar la ayuda: Sánchez \& Orti, 1997b: doc. XII (1353/03/15-04/2, 3, 24 i 29), p. 116. Por ende, parece razonable que el gobierno de la ciudad tuviera la precaución de distinguir claramente esta parte y de gestionarla al margen del resto de fuentes fiscales o ingresos.

8 Algunas de estas novedades ya fueron apuntadas por C. Guilleré: Guilleré, 2004: 39-55. Obviamente, encontramos figuras muy parecidas al clavari de les imposicions a partir de la misma época en otros municipios a lo largo y ancho de la Corona de Aragón. Sin embargo, según señala M. Sánchez, cabe destacar no tanto el fenómeno de división o duplicación de clavaries como la propia existencia de contabilidades separadas y, sobre todo, el carácter cerrado que adquirió la dedicada a la gestión del determinante binomio imposiciones/deuda: Sánchez, 1999: 472. En ese sentido, a partir de 1364 la clavaria de la ciudad de Barcelona se separó en dos (por un lado, la clavaria de l'assignació, dedicada a la gestión de la deuda censal; por el otro lado, la clavaria comuna, orientada a cubrir otros gastos de funcionamiento o extraordinarios), aunque permaneció en manos de un único oficial: Orti, 2007: 274. Por otra parte, se documenta la existencia de un tesorero llamado clavari dels anuals que pagaba pensiones de rentas en la ciudad de Manresa ya en 1364 (Torras, 1999: 165-166), y la existencia episódica (y como consecuencia de una crisis financiera) de una clavaria dels censals separada de la clavaria comuna en Valls entre 1407 y 1415 (Morelló, 2001: 887-891). Asimismo, en Valencia, en el año 1367, apareció el cargo de clavari de censals, encargado de satisfacer los intereses de la deuda, al lado de una clavaria comuna: García Marsilla, 2002: 252-256. En cuanto a otros casos de poblaciones del reino de Valencia: Furió, 1999: 52-53, 59. 
sistema de murallas u otras obras públicas, de organizar la defensa de la ciudad, de abastecerla de grano en tiempos de carestía, de enviar embajadas a la corte del rey, de preparar celebraciones extraordinarias en motivo de entradas de autoridades o de costear procesos judiciales en los que estaba inmersa la comunidad, entre otros hechos más esporádicos. Como consecuencia de todo ello, pudieron nombrarse desde el consejo municipal síndicos específicos y crear administraciones ad hoc, con cierta autonomía durante poco más de un año, pero sin llegar nunca a institucionalizarse ni el cargo ni la administración.

Por otra parte, ante este nuevo panorama de las décadas de 1360 y 1370, el antiguo tesorero, miembro del ejecutivo, se limitó a regir una caja con partidas de procedencia variada y destinada a finalidades aún más diversas y cambiantes en función de las mencionadas necesidades y de la constitución (o no) de cajas específicas. En un principio, el clavari dels jurats recibía la mayoría de derramas, recurso fiscal ya bajo control del municipio desde finales del siglo XIII que siguió utilizándose hasta las primeras décadas del siglo XV y de forma muy puntual posteriormente, quedando relegado a un segundo plano por los impuestos indirectos. Como contrapartida, este tesorero acabó obteniendo lo devengado por el arriendo de las barras o derechos de entrada y salida a la ciudad de mercancías de forasteros cobrados para propósitos específicos y por el arriendo anual del control de los pesos y medidas. ${ }^{9}$

Sin embargo, según apuntábamos, el uso tan recurrente que se hizo, en las últimas décadas del siglo XIV, de las emisiones de rentas consignadas sobre las imposiciones para hacer frente a la mayor parte de urgencias y el consiguiente peso creciente de la deuda censal muchas veces obligó a orientar casi todas las fuentes fiscales al alcance del municipio al servicio de ésta. De ahí que la clavaria de les imposicions ganara tanto protagonismo a partir, sobre todo, de las décadas de 1370 y $1380 . .^{10}$

9 Para una breve muestra de la gran variedad de tipos de ingresos y gastos de los clavaris del jurats, véase: AMGi, I.3.3.1.2., 1lig. 2, reg. 1 (1391); AMGi, I.3.3.1.1., llig. 16, reg. 3 (1405); AMGi, I.3.3.1.2., 1lig. 10, reg. 6 (1438). En cuanto a las barras, cabe especificar que en las últimas décadas de siglo XIV tendieron a destinarse a las costosas obras de reparación y mejora del sistema de murallas, de manera que su arriendo estuvo bajo control de los administradores específicos de estas obras. A partir de 1400, en cambio, se documenta con más frecuencia que los pagos de los arrendatarios fueran percibidos directamente por el clavari dels jurats. Véase, por ejemplo: AMGi, I.2.1., 1lig. 2, s.f., 1407/07/31; AMGi, I.2.1., 1lig. 3 bis, reg. 2, s.f., 1429/09/29.

10 En este sentido, en 1367 ya se asignaron al clavari de les imposicions las derramas aplicadas con tal de abordar nuevas peticiones de la Corona, una vez terminada la Guerra contra Castilla, o de financiar nuevas obras de amurallamiento y que conllevaron aumentos en el nivel de endeudamiento: AMGi, I.1.2.1., llig. 6, ff. 191r-193r, 1367/01/20. De hecho, entre 1367 y 1374, la figura del clavari dels jurats 


\section{El cargo de clavari de les imposicions: nombramiento, funciones y evolución entre 1355 y 1443}

Presentados sus orígenes, cabe indicar que el clavari de les imposicions era designado cada año por los jurats, a veces, pero no siempre, con el beneplácito del consejo. La elección acostumbraba a tener lugar entre el primer y el tercer mes de cada año, poco después del inicio de la legislatura que suponía, el día 1 de enero, el nombramiento de los nuevos integrantes del consejo de ochenta miembros, de los seis regidores (jurats), de los tres auditores de cuentas y de los dos supervisores urbanísticos (sobreposats de les obres). ${ }^{11}$ Además, tenía lugar poco después del inicio del ejercicio económico que representaba, en las postrimerías de diciembre, la subasta de impuestos para el año venidero por parte de los regidores salientes. Y, finalmente, coincidía con el comienzo en enero del calendario de pagos de las pensiones anuales de los títulos de deuda.

A pesar de quedar al margen de los mecanismos consuetudinarios de renovación de oficios municipales del día de año nuevo, parece que a lo largo del periodo estudiado siempre se accedió al cargo de clavari de les imposicions por designación y a cambio de una retribución establecida por los regidores o el consejo. A diferencia de otras localidades catalanas, no se documentan concesiones temporales a financieros que actuaran a título privado, ni el hecho de otorgar el oficio en pública almoneda. ${ }^{12}$

quedó eclipsada por el tesorero que controlaba la caja de los impuestos indirectos (o sea el clavari de les imposicions) e intentaba abordar las primeras renegociaciones de títulos de deuda y reducciones de intereses. En consecuencia, a menudo se considera a éste último como el único tesorero de la ciudad. Por otra parte, fue habitual que los pagos pendientes de contribuyentes que se retardaban en satisfacer lo que les correspondía fueran desde entonces asignados a los clavaris de las imposicions, nunca sobrados de recursos ante el gran número de acreedores a atender. Véase un ejemplo de ello en 1387 y en 1393: AMGi, I.1.1., n. 16 bis, ff. 18v-19r, 1387/01/16; AMGi, I.1.1., n. 28, ff. 10v-12v, 1393/12/04.

11 A diferencia del resto de oficiales, no existía un día fijo para el nombramiento del clavari de les imposicions. Mientras que en 1364 o en 1424 fue nombrado el mismo 1 de enero, en 1379 el día 6 de aquel mes, en 1441 el día 9, en 1367 el día 20, en 1405 el día 23, y en 1394 no fue hasta el 5 de febrero y en 1377 hasta el 20 de marzo. Respectivamente: vid. nota 2; AMGi, I.1.1., n. 47, ff. 6v-9r, 1424/01/01; AMGi, I.1.1., n. 9, ff. 23r-v, 1379/01/06; AMGi, I.1.1, n. 56, ff. 17r-19r, 1441/01/09; AMGi, I.1.2.1, 1lig. 6, ff. 191r-193r, 1367/01/20; AMGi, I.1.1., n. 39, ff. 18r-19r, 1405/01/23; AMGi, I.1.1., n. 29, ff. 36v-39v, 1394/02/05; AMGi, I.1.2.1, 1lig. 6, reg. 2, f. 36r, 1377/03/20.

12 Han sido bien estudiadas las tentativas del municipio de Cervera, a lo largo de la segunda mitad del siglo XIV, de sustituir el clavari por un financiero que se responsabilizara del pago de las pensiones de censals a cambio de la asignación de los ingresos comunitarios y de una sustanciosa retribución. Finalmente, se volvió al sistema del clavari, quien era contratado por los regidores después de ponerse el cargo a subasta y negociar varias condiciones: Verdés, 2004: 81-93, 109-115, 139-151. También se arrendaba la clavaria en la ciudad de Tarragona desde aproximadamente la década de 1370 hasta el año 1465: Cortiella, 1984: 259. 
Ello no obsta para que, como veremos, el desarrollo inicial de la clavaria de les imposicions, entre principios de la década de 1350 y comienzos de la siguiente, se fraguara precisamente a medio camino entre la banca privada de la ciudad y del arca común, se eligieran siempre vecinos con un perfil personal muy cercano al mundo de las finanzas o, más tarde, en circunstancias puntuales, se registren ofertas de varios individuos para desempeñar el oficio sin remuneración o a cambio de un salario por debajo de lo habitual. Asimismo, puede constatarse que prácticamente todos los individuos que fueron nombrados clavaris permanecieron en este puesto durante más de un año, hasta llegar a media docena de ejercicios seguidos o, de modo excepcional, a más de veinte (Cuadro 1).

Por lo que respecta a sus funciones, como hemos apuntado, el clavari de les imposicions era el tesorero que se ocupaba, en esencia, de la percepción del arriendo de los impuestos indirectos a varios individuos o compañías. ${ }^{13}$ Con ello pagaba mensualmente las pensiones de las rentas emitidas por la universidad; también los distintos salarios ordinarios del municipio, a saber, de los cargos políticos elegidos el 1 de enero y de los abogados, procuradores, escribanos, alguaciles y a veces médicos con una pensión a cargo de la ciudad, amén de retenerse su propia retribución.

Todo ello ya quedaba así dispuesto en las instrucciones, elaboradas por el consejo y los jurats, que los clavaris juraban en la toma de posesión del oficio durante las décadas de 1360 y $1370 .{ }^{14}$ A finales de este último decenio, sus atribuciones, obligaciones y actuaciones fueron definitivamente reguladas en distintas provisiones del infante Juan, primogénito del rey Pedro el Ceremonioso y duque de Gerona, especialmente en unas ordenanzas promulgadas en 1377, corregidas en 1379 y ratificadas en forma de privilegio perpetuo en $1386 .{ }^{15}$

13 Sobre estos impuestos indirectos en Gerona en la época que estudiamos, véase una primera aproximación en Guilleré, 1999: 423-445. Para el caso paradigmático de Barcelona: Orti, 1999: 399-422.

14 Conservamos las de 1364, 1366, 1367 y 1377 (meses antes de las disposiciones del infante Juan citadas más abajo). Respectivamente: vid. nota 2; AMGi, I.1.1., n. 6, f. 48v, 1366/01/19; AMGi, I.1.2.1, 1lig. 6, ff. 191r-193r: 1367/01/20; AMGi, I.1.2.1, 1lig. 6, reg. 2, ff. 36r, 1377/03/20.

15 La matriz del documento original de las ordenanzas: ACA, C, reg. 1723, ff. 38v-42r, 1377/11/10, Gerona. Existe también una acta de la publicación de estas ordenanzas, junto a algunas modificaciones significativas hechas a instancias de dos nuncios enviados a la corte del duque en febrero de 1379: AMGi, I.1.1, n. 9, ff. 2r-4v. A parte de constar en el registro de la Cancillería real correspondiente (ACA, C, reg. 1691, ff. 139r-141r, 1386/11/19), se conserva el original del privilegio de 1386 en el archivo de la ciudad (Boadas \& Casellas Serra, 2005: doc. 616) y fue copiado en uno de sus libros de privilegios: Guilleré, 2000: doc. 340. No debemos perder de vista el hecho de que todas estas disposiciones fueron promulgados a la par que desde el mismo entorno del primogénito se orquestraba una gran campaña 
Con pocas variaciones, los registros contables que se conservan, producto de la rendición de cuentas anual a la que estaba obligado dicho tesorero, muestran la relativa continuidad de los mecanismos expuestos hasta mediados del siglo XV. ${ }^{16}$ No obstante, cabe advertir que el peso efectivo y el margen de actuación del clavari de les imposicions respecto a otras cajas o administraciones ligadas al municipio pudieron variar en función de la coyuntura y de la evolución de la hacienda local.

Así, por ejemplo, en ciertos episodios como el de finales de la década de 1360 e inicios de la siguiente se documenta el recurso a la consignación directa del pago de las rentas a las imposiciones, o sea que tenían que hacerlo efectivo los propios arrendatarios de estos impuestos. ${ }^{17} \mathrm{Y}$, junto a ello, a pesar de varias provisiones reales que las prohibían, fueron habituales prácticas como la compensación fiscal, o sea la posibilidad de que los acreedores de rentas se cobraran los pagos semestrales en contraprestación de alguna deuda fiscal, sobre todo lo que tenían que tributar en las derramas e, incluso, lo que debían del precio del arriendo de imposiciones. ${ }^{18}$ A consecuencia de dichos mecanis-

para intentar sanear la deuda censal de la que era la capital de su ducado. Para un caso ilustrativo de la penetración de la monarquía en el regimiento de municipios en momentos de dificultades financieras, véase el de Calatayud en el tercer cuarto del siglo XIV: Diago, 2007: 346-349.

16 A grandes rasgos, todos siguen un esquema parecido. En primer lugar, se anotan, en el apartado de ingresos, los precios por los que se habían arrendado las imposicions a varios individuos y, sobre todo, a grupos o compañías. Posteriormente, en el capítulo de gastos, se consignan los pagos de las pensiones anuales de las rentas emitidas distribuidos en tandas semestrales, los salarios ordinarios de los oficiales municipales, la remuneración que se retiene para sí el clavario, otros gastos de procedimiento ligados al propio cargo y, en ocasiones, las primas prometidas a los pujadores en la almoneda de impuestos. Véase una pequeña muestra: AMGi, I.3.3.1.2., 1lig. 3, reg. 1 (1394, 1395) o AMGi, I.3.3.1.2., 1lig. 8, regs. 1 (1430), 2 (1431), 3 (1432).

17 Se constata a partir de referencias indirectas ya entre 1367 y 1369 (por ejemplo, AMGi, I.1.1, n. 6 bis, f. 80r, 1367/06/16 o AMGi, I.3.3.1.1., 1lig. 3, s.f., 1369/02/06), y explícitamente en el contrato de arriendo de las imposiciones en las anualidades de 1370 a 1373 (para ambos extremos: AMGi, I.3.3.1.1., llig 2, s.f., 1369/12/30; AMGI, I.2.1., 1lig. 7, s.f., 1372/12/29). En torno a 1400, a la vez que se suspendieron durante varios años el pago de pensiones de rentas, hubo un intento de repetirlo pero no cuajó: AMGi, I.3.3.1.1., llig. 12, ff. 167r-v, 1398/05/25; AMGi, I.1.1., n. 35, ff. 12v-14r, 1400/01/13; AMGi, I.3.3.1.1., 1lig. 13, reg. 2, s.f., (1400/04/20), s.f. (1401/01/11); AMGi, I.1.1., n. 36, f. 40v, 1401/08/22; AMGi, I.1.1., n. 36, ff. 88r-90r, 1402/01/0; AMGi, I.1.1., n. 38, ff. 19r-24r, 1403/02/03. Con este procedimiento aumentaba, sin duda, el protagonismo de los arrendatarios en perjuicio del control real del flujo de dinero por parte del clavari. Sabemos, asimismo, que en la cercana villa de Castelló d'Empúries, alrededor de 1381, también se arrendaban las imposiciones con asignaciones específicas de pensiones de censals y violaris cada una: Sánchez, 1999: 480-483.

18 Estrategias de este tipo ya pueden rastrearse en los primeros años que la hacienda local se endeudó emitiendo rentas (AMGi, I.1.2.1., 1lig. 5, reg 1, f. 207v, 1351/09/02). Aunque las ordenanzas del infante Juan las impidieran explícitamente (vid. nota 15), el consejo municipal consintió en más de una ocasión que el clavari las aceptara (AMGi, I.1.1., n.12, ff. 18r-19r, 1383/06/17; AHG, Gi-09, vol. 21, f. 178r 
mos, la moneda no siempre pasó por las manos del clavari, sino que este oficial pudo limitarse a certificar que los pagos se habían saldado. Obviamente, todas estas prácticas se vieron favorecidas por el hecho de que la mayor parte de acreedores del municipio fueron, al mismo tiempo, habitantes de la ciudad $\mathrm{y}$, por ende, contribuyentes de ella y potenciales arrendatarios de impuestos.

Asimismo, tenemos constancia del ejercicio por parte del citado clavari de otras funciones normalmente desarrolladas, según hemos explicado más arriba, por comisarios específicos, como la emisión de rentas o la renegociación de la deuda, la reclamación de impagos (tarea para la que en ciertas ocasiones se creó un cargo de tesorero ad hoc) o, en fases más tardías, la coordinación del abastecimiento de víveres para la ciudad. ${ }^{19}$ Esta dinámica también se registra en

1393/06/23). El rey Martín I también las autorizó en un contexto en el que el enorme volumen de la deuda fiscal obstruía la actividad de la tesorería (AMGi, I.3.3.1.1., 1lig. 13, reg. 2, s.f., 1401/02/17), aunque él mismo dio marcha atrás refiriéndose a una lejana provisión de su padre, Pedro el Ceremonioso (Guilleré, 2000: doc. 350, 1403/11/07). No obstante, años después, algunos ciudadanos siguieron «pagando» su parte correspondiente en las derramas remitiendo lo que se les debía en concepto de pensiones de censals, por ejemplo: AMGi, I.1.1., n. 43, ff. 52r-v, 1414/08/16. En las fases más críticas también se aceptó que algunos compradores de impuestos liquidaran parte del montante del arriendo mediante recibos de la percepción de pagos de rentas de su propiedad, e incluso de terceros que les habían cedido temporalmente sus derechos. Por ejemplo: AMGi, I.3.3.1.1., 1lig. 11, reg 3, s.f., 1396/06/28; AMGi, I.1.1., n. 39, ff. 8r-9r, 1404/12/11; AMGi, I.3.3.1.1., llig 11, reg 3, ff. 141v-142r, 1407/12/31.

19 Varios clavaris simultanearon dicho oficio con la responsabilidad de emitir deuda en nombre de la comunidad actuando como síndicos de ésta: P. Ferrer en 1378 (en pleno proceso de reducción de intereses de la deuda), J. Beuda en 1386 y 1387 (ante la necesidad de mejorar el sistema defensivo de la ciudad, de hacer un donativo al infante Juan y de reducir los intereses de algunos censals) y M. Vilar, que repitió en el cargo en numerosas ocasiones, en 1417, 1419, 1421, 1424, 1426, 1427, 1429, 1430, 1432 y 1433 (en operaciones tanto de refinanciación de la deuda, en las que actuaba con otros comisarios, como de emisión de nuevas para propósitos varios). Respectivamente: AMGi, I.3.3.2.4, 1lig. 15 (nombramiento como síndico en 1378/03/28). AMGi, I.3.3.1.5, llig. 2, regs. 1 y 2 (nombramientos en 1386/09/01, 1386/10/02, 1387/01/01, 1387/05/10). AMGi, I.3.3.2.4, UI 19103 (1417/11/10); AMGi, I.1.1., n. 45, ff. 38r-40v, 1419/06/30; AMGi, I.1.1., n. 46, ff. 16r-17v, 1421/01/01; AMGi, I.1.1., n. 47, ff. 73v-74r, 1424/03/02; AMGi, I.1.1., n. 48, ff. 23v-24r, 1426/04/20; AHG, Gi-01, vol. 401, s.f., 1427/11/21 .; AMGi, I.1.1., n. 49, ff. 71r-72v, 1429/05/06; AMGi, I.1.1., n. 50, ff. 42r-44r, 1430/11/14; AMGi, I.1.1., n. 50, ff. 42r-44r, 1430/11/14, AMGi, I.3.3.1.2., llig. 9, reg. 1. Como decíamos antes (vid. nota 10), los retrasos en los pagos de derramas y en los arriendos de impuestos a menudo se consignaron a la caja de la clavaria de les imposicions, por lo que el clavari fue nombrado específicamente para ocuparse de su recaudación. Por ejemplo, fueron explícitamente facultados para ello N. Gornall en 1380, J. Beuda en 1385 y en 1387, G. Julià en 1402 y 1403 y L. Tord en 1407. Respectivamente: AMGi, I.1.1., n.10, ff. 8r-10v: 1380/01/08; AMGi, I.3.3.1.5, 1lig. 2, regs. 1, ff. 2r-9v, 1390; AMGi, I.1.1., n 16 bis, ff. 18v-19r, 1387/01/16. AMGi, I.1.1., n. 37, f. 30r, 1402/06/07; AMGi, I.1.1., n. 36, f. 113r, 1403/05/22; AMGi, I.1.1., n. 40, f. 3r, 1407. A partir de esta última fecha parece como si esta ocupación pasara a ser inherente al cargo de clavari de les imposicions. En ese sentido: AMGi, I.1.1., n. 44, ff. 52r-v, 1418/12/30 o AMGi, I.1.1., n. 45, ff. 11r-12v, 1419/01/26. Contrariamente, en años puntuales como en 1384 o en 1400, se nombró un tesorero dedicado en exclusiva a los retrasos, el llamado clavari dels endarreriments o de les restes de les imposicions: AMGi, I.1.1, n. 13, ff. 22r-v, 1384/08/22; AMGi, 
otras poblaciones.$^{20}$ Además, en algún periodo concreto, se unificó la caja de las imposicions y la de los jurats, con el aparente propósito de encontrar fórmulas que dieran más fluidez a la satisfacción de los gastos. ${ }^{21}$ En definitiva, a pesar de la existencia de una tendencia general que se mantuvo, el cargo de clavari de las imposicions estuvo sometido a ciertas mutaciones más o menos puntuales.

\section{Una prosopografía de los clavaris de les imposicions de Gerona}

\subsection{Presuntos rasgos comunes de los clavaris}

Los cambios que acabamos de apuntar deben tenerse en cuenta a la hora de analizar cuáles eran los rasgos de los individuos que desempeñaron dicho oficio. A los gerundenses que fueron designados clavaris de les imposicions se les podrían suponer ciertas competencias técnicas, conocimiento de los mercados y solvencia económica. Todo ello sin olvidar que probablemente contaban con el consenso de los diversos grupos con intereses en la hacienda local, especialmente el de las familias con mayor peso político y el de las que destacaban entre el colectivo de los acreedores, amén de instancias no menos influyentes como la corte real. Precisamente, la bibliografía disponible para casos relativamente próximos al de Gerona o de otros territorios acerca de tesoreros de municipios tiende a destacar tanto los elementos económicos como los políticos y, aún más, la interrelación entre ambos. ${ }^{22}$

I.3.3.1.1., llig. 13, s.f., 1400/05/21, 1400/12/04 y 1401/02/17. M. Vilar, el clavari por antonomasia entre aproximadamente 1415 y 1438, también fue facultado, en el momento que ocupaba el cargo, para ejercer de administrador de la botiga del forment o almudín de la ciudad que entonces empezó el camino firme hacia su institucionalización: AMGi, I.1.1., n. 47, ff. 24v-25v, 1424/07/15. Evidentemente las cajas de la clavaria de les imposicions y la de este almudín debían comunicarse fácilmente, puesto que su gestor era la misma persona. Aún así, siempre se auditaron por separado.

20 Sin ir más lejos, en la ciudad de Barcelona, durante la década de 1350 e inicios de la siguiente, algunas veces los clavaris también se ocuparon de la venda de violaris y censals, aunque en otras ocasiones lo hicieron síndicos específicos: Orti, 2007: 266-269.

21 Se hizo concretamente entre 1429 y 1438, y se dejaron a cargo de M. Vilar: AMGi, I.1.1., n. 49, ff. $62 \mathrm{v}-63 \mathrm{v}, 1429 / 01 / 01$.

22 En el transcurso de todo el presente apartado se tendrán en cuenta, además de otras referencias puntuales, los ilustrativos ejemplos de los clavaris de la villa catalana de Cervera durante el Trescientos (Turull, 1990: 426-427), de los mayordomos ciudadanos del concejo de Sevilla entre aproximadamente 1370 y 1520 (Collantes, 2000: 13-39); y de los consuls boursiers de la villa occitana de Millau de los siglos XIV y XV (Garnier, 2006: 347-461). Véase, además, las interesantes comparaciones que se establecen en esta última publicación con otros enclaves de la geografía francesa objeto de algún estudio. 
Veamos a continuación si todas estas presunciones resultan ciertas en el caso de los 28 individuos que ocuparon el cargo de clavaris de les imposicions en el municipio de Gerona entre 1355 y $1443 .{ }^{23}$ Para ello intentaremos, mediante el método prosopográfico, determinar su extracción social, ámbitos de actividad profesional, patrimonios, las respectivas carreras en las distintas administraciones públicas, así como sus vínculos familiares, clientelares y la posible inserción en diversas redes. ${ }^{24}$

\subsection{Un patrón común, pero con variantes}

En primero lugar, cabe destacar que, salvo tres excepciones que comentaremos más adelante, quienes desempeñaron el oficio de clavari pertenecían al sector mercantil y formaban parte de la mà mitjana o estamento medio de la comunidad política de la ciudad (cuadro 1). La constatación, en efecto, no resulta demasiado sorprendente. ${ }^{25}$ De todos modos, tratemos de observar cuá-

23 Antes ya se ha justificado el uso del ejercicio de 1355 como referencia de inicio del estudio. En cuanto a emplear el año 1443 como término, cabe decir que, aunque la figura del clavari de les imposicions continuara probablemente (y a falta de investigaciones que permitan confirmarlo) hasta finales del siglo XV existiendo con unos rasgos básicos equivalentes a los consolidados en las décadas de 1380 y 1390, hay varias razones que lo explican. Por un lado, justamente en 1443 el municipio de Gerona obtuvo un privilegio para la creación de una banca municipal (Juliol, 2001: doc. 104, 1443/01/23). Y, a pesar de no concretarse entonces el proyecto, la simple iniciativa legislativa, junto a la inauguración de dos nuevas taules de canvi privadas y totalmente homologadas entre 1443 y 1445, después de muchas décadas de no existir ninguna en Gerona, pone de manifiesto un cambio de ciclo dentro de la evolución de los sistemas financieros de la región merecedor de un análisis atento que excedería los límites del presente trabajo (AHG, Gi-02, vol. 207, f. 115v-119v, 1443/10/01; AHG, Gi-01, vol. 426, s.f., 1445/ 01/23). Por el otro lado, en la misma legislatura de 1443, dentro del contexto de un proceso de reforma política de la institución municipal gerundense impulsado desde la corte del gobernador general de Cataluña y de la reina María de Castilla, en ausencia de su esposo Alfonso el Magnánimo, desde dichas instancias se intentó nombrar a dedo el gestor de la clavaria de las imposicions. Esta maniobra, sin embargo, topó con la vehemente oposición de las autoridades locales, que reivindicaron las concesiones realizadas por Pedro el Cereminoso, justamente entre finales de la década de 1350 e inicios de 1360 cuando vemos aparecer el oficio que nos ocupa. Según insistían, en ellas se reconocía a los gobiernos municipales del principado la plena capacidad de aplicar y administrar imposiciones, por lo que también tenían la exclusiva de escoger quien las recaudaría y quien las gestionaría, o sea quien sería el tesorero responsable de estas exacciones indirectas y de su destino (AMGi, I.1.2.1., 1lig 9, reg. 4, f. 43r (1443/05/15), 45r-v (1443/08/20), 46r (1443/08/20)). En cierto modo, ni que fuera a nivel simbólico, se cerraba el círculo reivindicando unos orígenes muy concretos para el cargo que tratamos.

24 Una referencia clásica sobre el uso de la prosopografía para el estudio de las sociedades hispánicas bajomedievales: Narbona, 1999: 31-49.

25 A título comparativo, vemos que en Tarragona, en un periodo parecido al estudiado para Gerona, de los 60 clavaris registrados, un 55\% eran de la mano mayor y un 36\% de la mediana: Cortiella, 1984: 261. Durante el siglo XV en la ciudad de Huesca el oficio de bolsero común, sin estar reservado en exclusiva a verdaderos especialistas en contabilidad, era ocupado preferentemente por mercaderes: Iranzo, 2005: 
les eran los atributos de los distintos sujetos que actuaron de tesoreros a la luz de las coyunturas que atravesó la administración financiera del municipio entre 1355 y 1443.

Como se ha intentado explicar en otro lugar, el concurso de cambistas o banqueros de la propia ciudad de Gerona resultó fundamental en la progresiva vertebración de un sistema fiscal y financiero municipal en las décadas centrales del Trescientos. ${ }^{26}$ En concreto, desde el decenio de 1330, los regidores recurrieron a los establecimientos de estos banqueros para la captación de crédito. Ello desembocó, en el contexto de la extraordinaria difusión de la deuda pública municipal a partir de los años 1350 , en el control por parte de dichos cambistas del producto de los impuestos indirectos, que, como se ha explicado más arriba, se consignaron al pago de las rentas emitidas. En consecuencia, la alternancia, entre 1355 y 1366, de los banqueros Ramon Medir y Ponç Malarç al frente de un cargo todavía en gestación supuso una institucionalización de las funciones financieras que desde décadas antes venían desempeñando estos titulares de taules de canvi privadas. Sin embargo, a finales de la década de 1360, asistimos a la aparición de nuevos actores, cuyo perfil también debemos poner en relación con nuevas coyunturas.

Superada la etapa llamémosla de los cambistas, comerciantes de todo tipo se sucedieron al frente de la clavaria de les imposicions: desde exitosos mercaderes como fueron los comerciantes de telas Bernat Ferrer o Jaume Beuda hasta boticarios que no quedaron nunca al margen de ciertos circuitos comerciales como Miquel Vilar o Guillem Coll. Entre todos ellos, algunos tenían una marcada orientación hacia el comercio de grano, productos textiles, pieles o esclavos, aunque lo más habitual es que combinaran más de una línea de negocio. ${ }^{27}$ Además, muchos entregaron productos en comandas comerciales

357-363. Parece similar, aunque con algún matiz distinto, la realidad de una ciudad mayor como Zaragoza. Allí, de 54 cargos documentados entre 1395 y 1496 la mitad eran mercaderes, pero existe una cuarta parte correspondiente a notarios, entre alguna otra profesión no mercantil. Y además bastantes de estos personajes eran distinguidos ciudadanos honrados: Lozano, 2007: 933-934.

26 Reixach, 2013: 179-194.

27 En ese sentido, podemos documentar, por ejemplo, que B. Cerir alternó en pocos años la transacción de productos tan diversos como los paños, el pastel, el cuero y, al mismo tiempo, hizo comandas de ganado a campesinos. Respectivamente: AHG, Gi-09, vol. 21, f. 195r, 1393/07/26; AHG, Gi-09, vol. 21, f. 202v, 1393/08/10; AHG, Gi-09, vol. 25, ff. 163r-v, 1396/08/05, AHG, Gi-06, vol. 118, s.f., 1408/07/13, AHG, Gi-09, vol. 21, f. 202v, 1393/08/10. F. Trilla, por su parte, tuvo un socio comercial instalado en Zaragoza en las décadas de 1350 y 1360. Él mismo, junto a su hermano Joan, probablemente estuvieron allí durante temporadas atentos a los circuitos laneros aragonés y castellano. Y, sin embargo, también vendió grano desde Aragón a una corporación de oficio de su ciudad natal: AHG, Gi-06, vol. 63 , 
con destino a varios puntos del Mediterráneo, otros, incluso, eran los socios capitalistas de sociedades mercantiles o tenían participaciones en ellas, y algunos, además, en embarcaciones de uso comercial. ${ }^{28}$ Sea como sea, en su conjunto, estos comerciantes eran hábiles en el manejo de dinero propio y ajeno, y algunos eran capaces de realizar operaciones muy similares a las de los banqueros sin ser titulares de un establecimiento propiamente bancario. ${ }^{29}$

Más allá de sus respectivos oficios y actividades profesionales, podemos documentar que todos, en mayor o menor medida, poseían inmuebles urbanos, equipamientos como molinos, explotaciones agrarias (desde casas fuertes o mansiones rurales hasta mansos), campos y huertos, además de percibir censos sobre todo este tipo de bienes o ser titulares de otras rentas como diezmos eclesiásticos. ${ }^{30}$

s.f., 1355/05/21; AHG, Gi-02, vol. 47, ff. 229v, 1385/12/05. Por otra parte, M. Santacília, a la vuelta de expediciones comerciales a la isla de Sicilia con el fin de colocar paños de producción catalana, traficaba con esclavos: AHG, Gi-10, vol. 61, s.f., 1414/01/20; AHG, Gi-02, vol. 133, ff. 36v-37r, 1418/06/27.

28 Por lo que respeta a las comandas comerciales, de casi todos los gerundenses que fueron clavari existen testimonios de haber librado en comanda mercancías, sobre todo telas elaboradas en los centros textiles de la demarcación de Gerona, para que fueran vendidas en varias plazas del Mediterráneo. Por ejemplo, lo hicieron F. Jalbert, L. Tord o B. Vilarnau: AHG, Gi-05, vol. 413, s.f., 1385/05/23; AHG, Gi-10, vol. 67, s.f., 1421/04/15; AHG, Gi-01, vol. 362, s.f., 1415/05/24. Asimismo, la mayoría de individuos que nos ocupan formaron parte de sociedades dedicadas al comercio de varios productos durante periodos más o menos largos de tiempo. Algunas extendieron su radio de acción a todos los territorios de la Corona de Aragón, como la que formó, junto a otros comerciantes, R. Provençal o, posteriormente, P. Tortosa (AHG, Gi-06, vol. 62, s.f., 1355/02/26, AHG, Gi-10, vol. 62, s.f., 1415/06/10); otras se limitaron a la gestión de una tienda de paños establecida en Gerona, como la de B. Ferrer y J. Beuda (AHG, Gi-05, vol. 311, ff. 16v-17v, 1377/04/08). Cabe destacar, además, que ciertas sociedades fueron fundadas por individuos previamente unidos por el parentesco, como fue el caso de F. Trilla y su sobrino R. Provençal (AHG, Gi-02, vol. 52, f. 134r, 1389/01/06) o el de B. Hospital y su hermano Guillem (AHG, Gi-06, vol. 64, s.f., 1355/05/16). Sabemos, finalmente, que tanto el hijo de F. Santceloni como M. Vilar tenían acciones en una nave bayonesa patroneada por marineros de Sant Feliu de Guíxols: AHG, Gi-01, vol. 333 bis, ff. 22r (1406/04/10), ff. 100r-v (1406/11/04). Y también las tuvo B. Cerir sobre la octava parte de una embarcación: AHG, Gi-09, vol. 24, f. 60r, 1395/01/29. Sobre todo este tipo de formas de organización comercial en Cataluña, véase los clásicos estudios: Madurell \& García Sanz, 1973; Madurell \& García Sanz, 1986, 2 vols.

29 En ese sentido destaca sobremanera la figura de M. Vilar, quien, a pesar de ser únicamente boticario y regentar una tienda de especias, fármacos y otros productos similares, recibió muchos depósitos de particulares o de corporaciones y realizó transferencias en una periodo en el que no hay rastro de la existencia de ningún establecimiento bancario privado en la ciudad. Entre otras muchas referencias, véase: AHG, Gi-10, vol. 61, s.f., 1414/03/05; AHG, Gi-01, vol. 401, s.f., 1427/07/25. Parecido fue el caso del comerciante B. Vilarnau, quien fue nombrado depositario de la corte real de Gerona y llegó a ser denominado cambista en alguna ocasión: AHG, Gi-02, vol. 166, ff. 34r-v, 1430/11/04; AHG, Gi-02, vol. 179, ff. 17r-28v, 1434/09/03.

30 Prácticamente todos eran propietarios de alguna vivienda (la mayoría de más de una) en el centro de la ciudad. Por ejemplo, J. Marcó vendió una casa a G. Julià en la calle de los merceros (AHG, Gi-05, vol. 411, s.f., 1383/02/20), mientras que J. F. Calvó alquiló uno en la cuesta de la iglesia de Sant Feliu (AHG, Gi-07, vol. 92, s.f., 1438/11/06). Otros, además, contaban con puestos en los distintos espa- 
Asimismo, vemos que participaban de forma asidua en el arriendo de frutos y emolumentos percibidos por instituciones eclesiásticas o linajes aristocráticos. ${ }^{31}$ Algunos de ellos también formaron parte de las compañías organizadas para el arriendo de la colecta de las generalitats dels draps, los impuestos sobre la producción y circulación de tejidos cobrados por la Diputación del General de Cataluña. ${ }^{32}$ Y, como no podía ser de otra manera, en su mayoría se muestran muy activos en la esfera del crédito, tanto en el ámbito estrictamente privado como en el generado por la extraordinaria difusión de la deuda pública. ${ }^{33}$ De ahí que todos adquirieran o heredaran en algún momento de sus vidas violaris y censals (rentas vitalicias o perpetuas) emitidas por varias poblaciones del área

cios del mercado, como L. Tord en la carnicería o G. Julià en la zapatería: AHG, Gi-11, vol. 24, s.f., 1403/04/06; AHG, Gi-06, vol. 107, s.f., 1405/11/17. Asimismo, P. Ferrer y B. Hospital tenían al menos un molino en el complejo destinado a la molienda de cereales para la población gerundense: AHG, Gi-05, vol. 414, s.f., 1386/05/01; ACA, C, reg. 1082, f. 19v, 1368/01/15. J. Beuda, en cambio, adquirió una torre equipada con un molino dedicado al procesamiento de la grana de pastel en las afueras de la ciudad: AHG, Gi-05, vol. 411, s.f., 1383/07/20. Unos pocos poseían algún edificio fortificado junto a caseríos y tierras de labranza, como M. Vilar en su entorno más inmediato: AHG, Gi-01, vol. 411, s.f., 1432/06/20; AHG, Gi-02, vol. 196, ff. 128r-129v, 1439/08/20. Otros simplemente tenían un conjunto de parcelas, quizás mayor de lo que las fuentes consultadas nos sugiere, como F. Trilla en el término de Juià y B. Ferrer y su mujer en el de Celrà: AHG, Gi-05, vol. 331, s.f., 1363/01/10; AHG, Gi-07, vol. 48, s.f., 1374/01/31. A otro nivel, por ejemplo, J. Beuda percibía numerosos censos sobre casas (AHG, Gi-05, vol. 414, s.f., 1386/05/23) y F. Santceloni sobre piezas de la huerta periurbana de Gerona (AHG, Gi-01, vol. 113, f. 7v, 1376/01/10). Finalmente, cabe señalar que P. Trilla era señor del diezmo de la parroquia ampurdanesa de Verges (AHG, Gi-09, vol. 35, s.f., 1408/03/31). En conjunto, véase sobre la necesidad de tener siempre presente la idea de diversificación de inversiones y de evitar falsas dicotomías entre ámbitos urbanos y rurales: Sabaté, 2009: 1-3.

31 A modo de ejemplo, B. Cerir participó, junto a varios artesanos conciudadanos suyos, en el arriendo de rentas asignadas al obispo de Gerona (AHG, Gi-05, vol. 460, s.f., 1386/06/08); J. Cavalleria en el de las correspondientes a la camarería del monasterio de Sant Pere de Galligants (AHG, Gi-04, vol. 95, s.f., 1427/12/03); mientras que G. Coll licitó en las del castillo principal de una importante familia de aristócratas, los Cruïlles (AHG, Gi-07, vol. 92, s.f., 1438/07/16).

32 B. Ferrer formó parte del grupo de arrendatarios de la colecta en la demarcación de Gerona de los años 1368,1373 y 1375, y del cuadrienio 1378-82 (donde también encontramos a J. Beuda): AHG, Gi-05, vol. 291, s.f., 1369/07/19; Ibid.., vol. 303, s.f., 1373/03/18, Ibid., vol. 306, s.f., 1375/01/05, vol. 313, f. 203v, 1381/09/24. El draper P. Tortosa también estuvo entre los miembros de alguna compañía de estas décadas de 1370 y 1380, igual que B. Hospital: AHG, Gi-07, vol. 53, s.f., 1375/12/08; AHG, Gi-05, vol. 313, f. 120v, 1380/12/18, AHG, Gi-03, vol. 32, f. 22r, 1382/04/18, AHG, Gi-09, vol. 15, s.f., 1389/03/04. M. Santacília, por su parte, participó en los arriendos del distrito gerundense de los periodos 1412-13, 1416-19, 1419-22, 1422-25 (en los tres últimos casos, junto al mercader P. Tortosa y L. Tord, entre otros socios) y 1425-28: ACA, G, G-24, vol. 4, f. 13r, 1412/05/18; Ibid., vol. 6, f. 12r-v, 1416/05/05; Ibid., vol. 6, ff. 65r-v, 1419/05/13; Ibid., vol. 6, f. 112v, 1422/05/14; ACA, G, G-54, vol. 1, ff. 191r-192v). Y B. Vilarnau también lo hizo probablemente en el trienio 1428-31: ACA, G, G-54, vol. 1, ff. 232r-233v. A propósito de las estructuras fiscales y financieras de la Diputación del General del principado: Orti, 2011: 119-137.

33 Acerca de los circuitos financieros en el área de Gerona, véase Sales, 2011: 135-154 
nororiental del principado, del Rosellón y, ya en el siglo XV, por la mencionada Diputación del General. ${ }^{34}$ Además, existen muestras claras del hecho de que los que ocuparon el oficio de clavari eran reputados como buenos conocedores del mercado de la deuda, puesto que fueron escogidos por particulares para invertir sumas importantes en los lugares que considerasen. ${ }^{35}$

Evidentemente, compraron títulos vendidos por el municipio de Gerona, del cual fueron acreedores. En ese sentido, sin estar entre los más pudientes, Bonanat Cerir, clavari en varios ejercicios entre 1380 y 1390 , o el mercader Pere Ferrer, que lo fue sólo en 1378, se hallaban entre la veintena de censalistas que poseían capitales superiores a 10.000 s.b. cuando sus títulos de deuda fueron novados en $1377 .{ }^{36}$ Aún más llamativo es el peso de Jaume Beuda que, tras servir al municipio durante un lustro entero, acumuló un gran patrimonio y adquirió varios censales para la dotación de diversas obras pías en los primeros años del siglo XV. ${ }^{37}$

Deberíamos fijarnos, por otra parte, en la consideración fiscal de estos tesoreros, a priori indicativa de su nivel de riqueza. Si nos basamos en una de-

34 Existe una gran cantidad de información sobre las inversiones realizadas en deuda pública por parte de los ciudadanos que fueron clavari, de igual manera que para muchos otros vecinos suyos que no ejercieron nunca el cargo. Entre muchos otros, fijémonos en el claro ejemplo que nos ofrece el heredamiento de B. Hospital a favor de su hijo homónimo cuando éste se casó en 1367. El que fue tesorero en 1374 donó a su primogénito la suma total de 20.000 s.b. Una pequeña parte se basaba en inmuebles o censos, otra porción un poco mayor estaba constituida por la participación en una sociedad mercantil y los 14.000 s.b. restantes consistían en rentas previamente adquiridas por el propio B. Hospital, en concreto: cuatro violaris emitidos por los regidores de la misma ciudad de Gerona en cuatro años diferentes, otro percibido del noble G. Galceran de Cabrenys y de Hostoles y las localidades de su señorío, y otros dos vendidos respectivamente por la villa rosellonesa de Cotlliure y los lugares de Canet y de Illa de la misma comarca: AHG, Gi-01, vol. 81, ff. 108r-116r, 1367/01/21. Puede compararse el mencionado caso con el de un mercader gerundense coetáneo, G. Bell-lloc, quien entre los años 1346 y 1371 se sabe que compró más de una veintena de rentas tanto de municipios como de particulares: Fernández Trabal, 1995: 106-113, 148-151. En una época un poco posterior, documentamos que familias como la de F. Santceloni compraron rentas emitidas por la Diputación del General de Cataluña (AHG, Gi-01, vol. 375, s.f., 1418/07/12; AHG, Gi-01, vol. 379, s.f., 1419/09/07) o que, incluso, B. Vilarnau adquirió un título de deuda de la Diputación del reino de Aragón (AHG, Gi-01, vol. 422, s.f., 1442/01/31).

35 Le sucedió a J. Beuda con un vecino de su pueblo natal o con un ciudadano barcelonés originario de Gerona: AHG, Gi-05, vol. 413, s.f., 1386/02/07; AHG, Gi-10, vol. 39, ff. 171v-172r, 1398/07/26. Algún otro, en cambio, fue designado procurador por parte de nobles con el fin principal de colocar la deuda emitida. Tal es el caso de P. Ferrer, síndico, junto a otro comerciante gerundense, del conde de Ampurias: AHG, Gi-01, vol. 95, ff. 5v-104r, 1370/11/06-08.

36 AMGi, I.3.3.2.4., 1lig 13, ff. 24v-25r, 70r-71v.

37 En cuanto a alguna de sus principales fundaciones, como un colegio para escolares en la ciudad de Gerona, véase: Juliol, 2001: docs. 74 (1398/12/24) y 75 (1398/12/24), y, por otra parte, AMGi, I.1.1., n. 38, ff. 65r-66v, 1403/11/29; AHG, Gi-01, vol. 399, s.f., 1426/02/18. 
rrama de 1390, podemos observar que, entre unos 1360 contribuyentes, sólo el mencionado Jaume Beuda y Francesc Santceloni se encuentran entre los 10 más grabados; y Bernat Ferrer, Guillem Julià, Francesc Trilla, el heredero de Pere Ferrer y Bonanat Cerir entre los $40 .{ }^{38}$

En suma, todo ello probablemente nos pone de relieve que, por norma general, no estamos ante las mayores fortunas de la ciudad de Gerona del periodo. De hecho, como ya se ha apuntado, sólo se adscriben al estamento superior de la comunidad, o sea a las familias que se denominaban de la mano mayor, Francesc Santceloni, el cambista Ponç Malarç y Narcís Gornall. Además, dejando a un lado el incuestionable perfil elevado del primero, los otros dos, aun perteneciendo al estamento mayor, no compartían los rasgos más comunes de sus principales miembros. En pocas palabras, no llegaron nunca a ejercer el cargo de regidor (jurat) a diferencia de parientes directos suyos, probablemente al no pertenecer a las ramas principales de las respectivas familias. ${ }^{39}$

$\mathrm{Si}$, finalmente, tratamos de detectar cuáles eran los aspectos coincidentes en las trayectorias político-financieras ligadas al municipio de los individuos que ocuparon el cargo de clavari de les imposicions, observamos vías bastante dispares (cuadro 1). Huelga decir que por ley no estaba permitido combinar en un mismo año el desempeño de un oficio municipal con el arriendo de impuestos indirectos, aunque sí se contemplaba la posibilidad de adquirir rentas emitidas por el municipio o concederle préstamos. ${ }^{40}$

38 AMGi, VIII.1.1., R 26638, 1390. Esta circunstancia contrasta bastante con lo que detecta F. Garnier en Millau, donde a finales del siglo XIV la gran mayoría de los tesoreros estaban entre los vecinos más grabados de la villa: Garnier, 2006: 416-418.

39 Así, en una carta dirigida al Papa de Roma, los jurats gerundenses no dudaron a definir a Santceloni como uno de sus conciudadanos más relevantes y «vir multum notabilis» que siempre trabajó para la «república» de la misma: AMGi, I.1.2.1, 1lig. 8, reg 3, s.f., 1409/08/20. El extenso patrimonio que se deduce de su último testamento parece que avala dichas consideraciones: Boadas \& Casellas, 2005: doc. 792 (1422/06/10). El cambista P. Malarç era hijo de un ciudadano señor de un castillo por concesión real, hermano, cuñado y tío de eminentes juristas, aunque él centró siempre su actividad en el comercio y la banca: Reixach, 2013: nota 22. En cuanto a Gornall, vid. nota 51.

40 Todo ello quedaba estipulado en las ordenaciones acerca de la hacienda municipal de 1377: vid. nota 15. Obviamente, estas disposiciones legales poco podían hacer con los pactos privados que se urdiesen tras la firma de los contratos. Aun así, en alguna ocasión extraordinaria, el representante de la administración real a la ciudad tuvo que consentir excepciones a la mencionada restricción, como por ejemplo en 1406, ya que, ante el auge de parcialidades y enfrentamientos, se aducía que, para ocupar los puestos del consejo, era imposible encontrar vecinos que no estuvieran implicados en el arriendo de impuestos de aquel año: ACA, C, reg. 2203, ff. 73r-74r, 1406/02/25. 
Dicho esto, constatamos que, con pocas salvedades, los diferentes tesoreros, con mayor o menor frecuencia, ocuparon alguna vez el cargo de regidor (jurat) de su respectivo estamento, el de auditor de cuentas o el de tasador de derramas, tanto antes como después de ser clavaris. ${ }^{41}$ Sin embargo, ninguno de ellos destacó demasiado respecto a otros ciudadanos. Por otra parte, los que poseían comparativamente un currículum más completo de cargos, de representaciones de la ciudad en el exterior y, asimismo, de participaciones en el arriendo de impuestos o de préstamos a la hacienda local fueron nombrados justamente tesoreros en los años de dificultades financieras del último tercio del siglo XIV e inicios del siguiente; un dato sin duda a retener. ${ }^{42}$

\subsection{Del individuo a las redes financieras y políticas}

Sea como fuere, no podemos limitar el análisis al perfil estrictamente personal de la nómina de individuos que fueron clavaris de les imposicions. No se trataba de hombres con habilidades financieras ajenos a la sociedad de la época, sino de gerundenses con sus compañeros de profesión, sus socios o sus avaladores, así como sus parientes, sus alianzas familiares y sus allegados en general.

41 En este punto debemos recordar los sugerentes planteamientos que hacen F. Garnier y M. Turull en torno a la carrera de los tesoreros municipales, tanto en la fase anterior a la primera vez que desempeñaron el cargo como en la de después. En cuanto al recorrido previo, Garnier concluye que en Millau no puede considerarse que el oficio de tesorero se inscribiera forzosamente en un cursus honorum dentro del gobierno municipal, puesto que documenta bastantes ejemplos de individuos nombrados boursiers sin haber ocupado antes el cargo de consul, de carácter marcadamente político. De todos modos, la mayor tendencia a tener experiencia política previa o no la vincula a la evolución general de la sociedad local y, en especial, a los cambios de mayor calado acaecidos en las filas de sus familias dominantes entre la segunda mitad del siglo XIV y la primera del siguiente: Garnier, 2006: 402-407. Por contraste, M. Turull centra la atención en la trayectoria posterior al cargo de tesorero y para los clavaris de Cervera de 1332 a 1395 apunta la hipótesis de que dicho oficio pudo servir de «catapulta política» para introducirse a los círculos restringidos de los cargos electos: Turull, 1990: 426-427. En cuanto a la ciudad de Gerona, parece que se observa algo parecido a Millau a propósito de la etapa previa a ser tesorero. En cambio, casi no se encuentran casos de individuos que fueran nombrados tesoreros y, con posterioridad a este importante papel dentro de la administración financiera, fueran designados regidores en repetidas ocasiones. Por ejemplo, no habían sido jurats antes de ser clavaris F. Jalbert, J. Beuda o G. Julià, pero luego sólo formaron parte del ejecutivo del gobierno municipal una sola vez (cuadro 1).

42 Pensamos, sobre todo, en los casos de P. Ferrer que fue clavari en pleno periodo de renegociación de la deuda y de suspensión del pago de las pensiones de 1377-1380, o de F. Santceloni en otra coyuntura muy parecida entre los años 1397 y 1400 (cuadro 1). El caso de F. Santceloni se interpretará desde una óptica complementaria más adelante. 
En esta sentido, cabe señalar que en la toma de posesión del cargo un par o más de conciudadanos acostumbraban a comprometerse a aportar avales para el nuevo tesorero. ${ }^{43}$ Asimismo, como ya hemos apuntado, pese a no constituir por lo general las fortunas más importantes de la ciudad, sí que se tuvieron una notable capacidad de crédito fruto de su integración en los circuitos financieros de la época. No en vano, y aunque resulte difícil de rastrear en las fuentes contables conservadas, la gestión de la clavaria suponía a quien desempeñaba el oficio efectuar anticipos y préstamos para hacer frente al calendario de pagos, en especial para aquellos que más años se perpetuaron en el cargo y controlaron otras cajas aparte de la de los impuestos indirectos, como ejemplifica la larga trayectoria de Miquel Vilar. ${ }^{44}$

Las aptitudes técnicas, cierta solvencia y, sobre todo, la inserción en las redes comerciales y financieras eran, por tanto, una condición indispensable para ser nombrado tesorero. No obstante, sin negar la importancia de estos aspectos, resulta difícil pensar que nadie pudiera llegar a un puesto tan decisivo en la administración financiera si no era con el suficiente respaldo. De hecho, la mayor parte de ellos, sin formar parte de la cúspide social de la ciudad, sirvieron a los intereses de los más poderosos en lo económico y lo político. Y ello tal vez tenga relación con la forma en la que, como hemos visto, el cargo de clavari era elegido, o sea a discreción del ejecutivo y la aprobación posterior del consejo. En cualquier caso, documentamos que muchos de ellos, a pesar de ser comerciantes o pertenecer al estamento medio, estaban emparentados con los grandes ciudadanos gerundenses.$^{45}$ Esta circunstancia también

43 Entre otros, véase el ejemplo de N. Gornall en 1380, cuando tuvo entre sus avaladores miembros destacados del estamento superior de la ciudad, además de su primo B. Vic y de su sobrino F. Gornall (AMGi, I.1.1., n.10, ff. 8r-10v, 1380/01/18), o el de P. Net en 1394, también secundado por destacados ciudadanos, a parte de su mujer y de sus hermanos (AMGi, I.1.1., n. 29, ff. 36v-39v, 1394/02/05). A propósito de la importancia del afianzamiento para ocupar determinados oficios en los concejos castellanos: Jara Fuente, 2006: 16-18, 24-25.

44 Ante lo que se ha podido demostrar para casos cercanos como el de la villa de Cervera de la década de 1440, a pesar de la escasez de evidencias claras existente en Gerona en ese sentido, resulta imposible no suponer un activo papel financiero al individuo que se situaba al frente de la tesorería: Verdés, 1999: $1134-1164$

45 Un buen ejemplo de ello lo encontramos en J. Marcó, cuya madre descendía de los Sunyer, una de las estirpes con mayor protagonismo en el gobierno municipal de Gerona a lo largo del Trescientos. Él mismo, sin ir más lejos, actuó de tutor de los hijos de uno de sus miembros más influentes: AHG, Gi-05, vol. 445, f 80v, 1396/03/24. Acerca de los Sunyer: Guilleré, 1994: vol. I , 266, 268-269, 272, 274-275. En cuanto a las alianzas entre las familias de la mano mayor con mercaderes en ascenso: Guilleré, 1984: 80-87. 
se registra en otros lugares. ${ }^{46}$ Asimismo, algunos, sin ser parientes, actuaron como agentes de prohombres destacados en asuntos particulares. ${ }^{47}$

Con todo, aún parece más llamativa otra dimensión. Y es que, por ejemplo, un hermano de Ramon Provençal trabajara en la tesorería del infante Juan, primogénito del Ceremonioso, coincidiendo con una época de notables exigencias de la corte real entre finales del decenio de 1360 y mediados del siguiente, que G. Julià estuviera casado en segundas nupcias con una hija de Bonanat Nadal, notario y escribano del rey Juan I, o que G. Coll fuera pariente de otro oficial regio. ${ }^{48}$ Algo parecido podría desprenderse del caso de Pere Tortosa, comerciante y, a la par, durante muchos años, gestor de negocios de Jaspert de Campllong, funcionario destacado de la tesorería del rey, y una de las grandes fortunas gerundenses y con más poder durante la segunda mitad del siglo XIV.49

Todas estas observaciones seguramente nos llevarían a la cuestión del emplazamiento de los municipios dentro de las estructuras políticas del principado bajomedieval y de la influencia que pudo ejercer en ellos el entorno regio mediante los estrechos lazos trabados con las elites locales. Sin querer entrar aquí en este complejo tema, sólo podemos añadir una constatación más. Mientras que no parece que el ejercicio del cargo de clavari fuera el paso inevitable para acceder al ejecutivo del gobierno local, sí que sucede, y tal vez no sea coincidencia, que algunos de los que lo desempeñaron llegaron también a ocupar ciertos puestos en la administración real o en la de la Diputación del General. Hubo quienes fueron lugarteniente del

46 A. Collantes también detecta muchas relaciones (entre otras el parentesco) entre los mayordomos de Sevilla y la oligarquía que detentaba el poder concejil: Collantes, 2000: 29-33.

47 Cabe destacar en este sentido que M. Vilar, incesante en su actividad, fue a menudo procurador de familias de relieve antes de ser clavari y por supuesto en el transcurso del largo periodo en el que ocupó dicho cargo. Véase, por ejemplo: AHG, Gi-10, vol. 57, s.f., 1414/03/13; AHG, Gi-01, vol. 362, s.f., 1414/05/22; AHG, Gi-01, vol. 376/377, s.f., 1419/01/09.

48 Acerca de N. Provençal: AHG, Gi-02, vol. 11, ff. 53r-v, 1371/10/09. De hecho, tres de los individuos que fueron clavaris en más ocasiones en las décadas de 1360, 1370 y 1380, F. Trilla, R. Provençal y B. Cerir, estaban estrechamente emparentados siendo los dos últimos sobrinos del primero y, por tanto, primos uno del otro. A propósito del parentesco de G. Julià y B. Nadal: AHG, Gi-09, vol. 11, s.f., 1387/06/23. El contexto en el que G. Coll fue nombrado tesorero era posterior al de Provençal, aunque similar debido a la influencia ejercida desde la Corona a la ciudad, entonces por parte de la reina María, mujer de Alfonso el Magnánimo. En cualquier caso, una de las dos sobrinas de G. Coll era esposa de Nicolau Roca, un escribano de dicha reina: AHG, Gi-01, vol. 421, s.f., 1440/01/21.

49 Entre otras referencias a propósito de P. Tortosa: AHG, Gi-05, vol. 96, F 24v, 1357/11/07. También J. Gironella, escribano, fue procurador de los descendientes de J. Campllong en varias situaciones: AHG, Gi-11, vol. 20, f. 51v, 1400/04/02. En cuanto a la figura de J. Campllong, véase Guilleré, 1994: vol. I, p. 74; vol. II, pp. 16-18, 255, 327, 329-330. 
veguer o bailes reales en la misma Gerona o en otras localidades, en general (aunque no siempre) después de haber sido los actores principales de la hacienda local. ${ }^{50}$ Por ende, tal vez la tesorería de la capital gerundense fuese un buen lugar para ganar prestigio ante una eventual carrera dentro de la administración real o la del General, o un puesto en el que formarse los vástagos de familias que ya se habían introducido en las filas del funcionariado de la Corona.

Si volvemos a centrar la mirada en el municipio, debemos insistir en la importancia de las relaciones de los tesoreros en el plano personal o político fijándonos en un último aspecto. Como se ha tratado de mostrar, el oficio de clavari de les imposicions conllevaba, excepto en coyunturas puntuales, un gran control de las finanzas. Por ello se intuye que pudo ser un oficio propicio para que los principales acreedores de la hacienda local (en una proporción importante los que también contaban con mayor presencia en el gobierno municipal) promovieran en él un pariente de una rama secundaria que pudiera ser, al mismo tiempo, tío, primo o cuñado de varios ciudadanos de peso. Puede aducirse aquí el caso de Narcís Gornall quien, a pesar de pertenecer a una familia acaudalada y con un vasto patrimonio sin ser el heredero principal de ella, y, en cambio, habiéndose casado con la hija de un pañero y dedicado sobre todo el comercio, tenía entre sus parientes cercanos algunos de los principales censalistas de las décadas de 1370 y $1380 .^{51}$

50 R. Provençal fue sots-veguer de Gerona entre 1369 y 1372: Guilleré, 1994: vol. I, p. 136. M. Santacília, baile de la ciudad entre 1416 y 1419: AHG, Gi-01, vol. 386 bis, s.f., 1421/09/24. Por otra parte, B. Ferrer fue diputado local de la Diputación del General en Gerona entre finales de la década de 1370 y principios de la de 1390 (AHG, Gi-05, vol. 422, s.f., 1385/07/12) y asimismo ocupó el cargo de lugarteniente del veguer de Gerona en el trienio 1380-1383 (Guilleré, 1994: vol. I, p. 137) y del Rosellón entre 1383 y 1386 (ACA, C, reg. 978, ff. 84r-v, 1386/09/10). Pere Trilla, hijo de F. Trilla, cuyas relaciones con el entorno del infante Juan veíamos antes (vid nota 48), fue baile de la villa de Sant Feliu de Guíxols entre 1385 y 1388 (con anterioridad pues al oficio de clavari: AHG, Gi-11, vol. 8, s.f., 1388/11/29), nombrado veguer y baile en la ciudad de Vic entre 1416 y 1419 (Junyent, 1969: 55) y, finalmente, lugarteniente del baile general de Cataluña en la demarcación gerundense en la década siguiente (AHG, Gi-08, vol. 9, s.f., 1424/05/27). Un ejemplo claro de haber ejercido algún cargo en la administración real antes de asumir la tesorería también sería el de J. Cavalleria, baile real de la villa de Besalú en torno a 1426, aunque él mismo vivió un ascenso posterior siendo nombrado auditor de cuentas de la Diputación del General de Cataluña: AHG, Gi-05, vol. 463, s.f., 1426/04/24; Sánchez de Movellán, 2004: 166. En cuanto a la siempre útil comparación con la villa de Millau, en este punto cabe señalar que en Gerona el panorama era sensiblemente distinto al de esta población occitana, donde no se detectan tesoreros que hicieran carrera en las cortes de señores de la zona o del estado de la Rouergue: Garnier, 2006: 425 y 461.

51 Algunas de las referencias que demuestran todos estos hechos son: AHG, Gi-01, vol. 190, ff. 132r-134r, 1371/11/05; AHG, Gi-04, vol. 48, s.f., 1380/06/19; AHG, Gi-05, vol. 412, ff. 14r-16v, 1384/10/28 
En otras circunstancias precisas, las grandes familias pudieron ponerse personalmente al frente de la administración financiera. Intereses como los creados sobre los títulos de deuda emitidos por una institución no eran intereses de una única persona, sino que estas rentas muy a menudo se encontraban en la base de la economía de toda una familia, e incluso podían constituir el sólido nexo de unión de muchos matrimonios. Así, destacan dos ocasiones en las que una gran familia se situó, a través de sus miembros principales, al frente la administración la clavaria de les imposicions. Nos referimos a los ejercicios de 1397 y 1400, una etapa de colapso en el pago de la deuda censal, cuando un hombre de la talla de Francesc Santceloni, miembro activo de la mano mayor y descendiente de una familia patricia protegida por la casa real, se ofreció a los regidores para administrar la tesorería sin percibir ningún salario por ello..$^{52}$

\section{Consideraciones finales}

La presente aproximación a un análisis prosopográfico a los individuos que fueron clavaris de les imposicions en la ciudad de Gerona entre 1355 y 1443 nos permite extraer varias conclusiones. En una primera parte, hemos repasado los orígenes de esta tesorería de la capital gerundense destinada en exclusiva a los ingresos del arriendo de los impuestos indirectos bajo control del municipio y destinados al pago de los intereses de las rentas (violaris y censals) vendidas en nombre de la comunidad. Y hemos comprobado que la clavaria llamada de les imposicions cristalizó en el momento que la deuda se consolidó definitivamente alrededor de 1360 y la situación exigió novedades institucionales.

Su aparición se acompañó de una reestructuración de la hacienda que incluía alguna otra administración e incluso tesorería, especialmente la que se-

Además era socio de algunas familias acaudaladas como los Segurioles o Malarç en una sociedad dedicada al mercadeo de telas: AHG, Gi-04, vol. 48, f. 5v, 1380/06/19.

52 Recordemos el perfil de Santceloni: vid. nota 39. Tan distinguido prohombre sólo pedía que los jurats hicieran las correspondientes asignaciones a los acreedores y perceptores de salarios ordinarios sobre los precios de las distintas imposiciones. Y él se aseguraría que todos estos procedimientos funcionaran: AMGi, I.1.1., n. 35, ff. 22v-23r, 1400/01/21. A propósito de las asignaciones realizadas que quizás a la larga no fructificaron: vid. nota 16. Santceloni, de entrada, salió adelante con su propuesta, aunque también se había ofrecido el mercader Pere Tortosa (quien sabe si representando otras familias con intereses distintos a los de Santceloni) para ejercer el cargo a cambio del salario de un único marco de plata: AMGi, I.1.1., n. 35, ff. 12v-14r, 1400/01/13. 
guía controlada por los miembros del ejecutivo. Después de un periodo de varios ajustes, a la altura de 1390 las funciones del responsable de la clavaria de les imposicions, nombrado a veces de forma unilateral por los regidores y otras reunido todo el consejo, pero siempre según criterios más bien políticos, quedaron fijadas. Con todo, en algunos aspectos se produjeron cambios marcados por la coyuntura, como la ampliación de competencias y tareas de dicho tesorero o de las fuentes fiscales que debía administrar.

Asimismo, la investigación prosopográfica nos ha mostrado que la práctica totalidad de los ocupantes del oficio fueron miembros del estamento medio de la ciudad. Asimismo, podemos refrendar las características comunes más o menos previsibles de la habilidad en el manejo del dinero, el conocimiento de los mercados y la inserción en las redes comerciales y financieras del momento, en el sentido de que ponían al servicio de las finanzas públicas estructuras de negocio, circuitos e información de gran utilidad.

Sin embargo, los resultados obtenidos nos advierten de la necesidad de contemplar la diversidad de perfiles y trayectorias más allá de los rasgos mencionados, sobre todo si atendemos a las etapas cambiantes por las que pasó la hacienda local de Gerona en un periodo de tiempo relativamente largo. Dificultades financieras o intereses creados pueden inducirnos a destacar otras vertientes de las figuras de estos tesoreros como serían sus vínculos familiares o contactos de todo tipo. Sin duda, estos contactos invitan a reflexionar acerca de la importancia de conceptos como el de capital relacional a la hora de comprender el papel ejercido por individuos no excesivamente ricos o poderosos aunque bastante activos en organismos como las administraciones locales.

En definitiva, según se ha procurado exponer, el análisis de los sujetos que se ocuparon de la gestión del endeudamiento a largo plazo y de los resortes fiscales principales del municipio de Gerona puede proporcionarnos algunas de las claves más interesantes para interpretar la institución, su funcionamiento y, sobre todo, su incardinación en las redes financieras y en las estructuras sociales y políticas de la época.

\section{Referencias Bibliográficas}

ABELLA SAMITIER, J. (2009), «La deuda pública de los municipios aragoneses en los siglos XIV y XV», Anuario de Estudios Medievales, 39/1, pp. 47-64.

BOADAS RASET, J., CASELLAS SERRA, Ll. E. (2005), Catàleg de pergamins del fons de l'Ajuntament de Girona (1144-1862), vol. I, Girona, Ajuntament de Girona. 
COLLANTES DE TERÁN SÁNCHEZ, A. (2000), «La élite financiera en la Sevilla bajomedieval: los mayordomos de concejo», Revista d'Història Medieval, 11, pp. 13-39.

CORTIELLA ÒDENA, F. (1984), Una ciutat catalana a les darreries de la baixa edat mitjana: Tarragona, Tarragona, Diputació de Tarragona.

DIAGO HERNANDO, M. (2006), «Haciendas municipales en el reino de Aragón durante el siglo XIV: El caso de Calatayud y su comunidad de aldeas», en D. Menjot y M. Sánchez (eds.), Fiscalidad de Estado y fiscalidad municipal en los reinos hispánicos medievales, Madrid, Casa de Velázquez, pp. 335-356.

FERNÁNDEZ TRABAL, J. (1995), Una família catalana medieval. Els Bell-lloc de Girona 1267-1533, Barcelona, Ajuntament de Girona - Publicacions de l'Abadia de Montserrat.

FURIÓ DIEGO, A. (1999), «Deuda pública e intereses privados. Finanzas y fiscalidad municipales en la Corona de Aragón», Edad Media. Revista de Historia, 2, pp. 35-79.

GARCÍA MARSILLA, J. V. (2002), Vivir a crédito en la Valencia medieval: De los orígenes del sistema censal al endeudamiento del municipio, Valencia, Publicaciones de la Universidad de Valencia.

GARNIER, F. (2006), Un consulat et ses finances: Millau (1187-1461), Paris, Comité pour l'Histoire économique et financière de la France.

GUILLERÉ, C. (1984), Diner, poder i societat a la Girona del segle XIV, Girona, Ajuntament de Girona.

- (1994), Girona al segle XIV, Girona, Publicacions de 1'Abadia de Montserrat, 2 vols.

- (1996), «Les sources financières et fiscales de Gérone à la fin du Moyen Âge», en D. Menjot y M. Sánchez (coords.), La fiscalité des villes au Moyen Âge (France méridionale, Catalogne et Castille), 1, Étude des sources, Toulouse, Privat, pp. 45-56.

- (1999), «Un exemple de fiscalité urbaine indirecte: les imposicions géronaises aux $\mathrm{XIV}^{\mathrm{e}}$ et XV $\mathrm{XV}^{\mathrm{e}}$ siècles», en D. Menjot y M. Sánchez (ed.), La fiscalité des villes au Moyen Âge (Occident méditerranéen) 2, Les systèmes fiscaux, Toulouse, pp. 423-445.

- ed. (2000), Llibre Verd de la Ciutat de Girona (1144-1533), Girona: Fundació Noguera-Ajuntament de Girona.

- (2004), «Structures et pratiques de gestión financière et fiscale à Gérone à la fin du Moyen Âge», en D. Menjot y M. Sánchez (coords.), La fiscalité des villes au Moyen Âge (Occident méditerranéen), 4 (La gestion de l'impôt: méthodes, moyens, résultats), Toulouse, Privat, pp. 39-55

IRANZO MUÑ̃IO, M. T. (2005), Élites políticas y gobierno urbano en Huesca en la Edad Media, Huesca, Ayuntamiento de Huesca.

JARA FUENTE, J. A. (2006), «Identidad corporativa y constitución política urbana: solidaridades económicas y poder en el marco de los procesos de afianzamiento de 
las rentas concejiles» en Y. Guerrero (coord.), Fiscalidad, sociedad y poder en las ciudades castellanas de la Baja Edad Media, Madrid, Ediciones de la Universidad Autónoma de Madrid, pp. 11-60.

JULIOL, G., ed. (2001), Llibre Vermell de la ciutat de Girona (1188-1624), Girona, Ajuntament de Girona-Fundació Noguera.

JUNYENT SUBIRÀ, E. (1969), Jurisdiccions i privilegis de la ciutat de Vich, Vic, Patronat d'Estudis Ausonencs.

LOZANO GRACIA, S. (2007), Las elites en la ciudad de Zaragoza a mediados del siglo XV: la aplicación del método prosopográfico en el estudio de la sociedad, Zaragoza, Universidad de Zaragoza, Tesis doctoral inédita.

MADURELL MARIMON, J. M. y GARCÍA SANZ, A. (1973), Comandas comerciales barcelonesas de la Baja Edad Media, Barcelona, CSIC.

- (1986), Societats mercantils medievals a Barcelona, Barcelona, Fundació Noguera, 1986, 2 vols.

MORELLÓ BAGET, J. (2001), Fiscalitat i deute públic en dues viles del Camp de Tarragona: Reus $i$ Valls, segles XIV-XV, Barcelona: CSIC-IMF.

NARBONA VIZCAÍNO, R. (1999), «El método prosopográfico y el estudio de las élites de poder bajomedievales», en El Estado en la Baja Edad Media. Seminario de Historia Medieval, Zaragoza, Universidad de Zaragoza, pp. 31-49.

ORTI GOST, P. (1999), «Les imposicions municipales catalanes au XIVe siècle», en D. Menjot y M. Sánchez (ed.), La fiscalité des villes au Moyen Âge (Occident méditerranéen) 2, Les systèmes fiscaux, Toulouse, pp. 399-422.

- (2006), «La distribución de la carga fiscal entre las ciudades y villas de realengo en la Cataluña del siglo XIV», en D. Menjot y M. Sánchez (eds.), Fiscalidad de Estado y fiscalidad municipal en los reinos hispánicos medievales, Madrid, Casa de Velázquez, pp. 275-316.

- (2007), «Les finances municipals de la Barcelona dels segles XIV i XV: Del censal a la Taula de Canvi», en M. Sánchez, (coord.). El món del crèdit a la Barcelona medieval, Quaderns d'Història, 13, Barcelona, Ajuntament, pp. 257-282.

- (2011), «Les finances de la Diputació del General de 1380 a 1462», en M. T. Ferrer i Mallol (dir.), Història de la Generalitat de Catalunya: Dels segles medievals a l'actualitat, 650 anys, Barcelona, Institut d'Estudis Catalans, pp. 119-137.

REIXACH SALA, A. (2013), «Finanzas municipales y banca privada en la Cataluña bajomedieval: los cambistas y la hacienda local de Gerona (1330-1380)», en C. Villanueva Morte et alii (eds.), Estudios recientes de jóvenes medievalistas Lorca 2012, VI Simposio Internacional de Jóvenes Medievalistas, Murcia, EditumSEEM-Universidad de Murcia, pp. 179-194.

SABATÉ CURULL, F. (2009), «Oligarchies and social fractures in the cities of late medieval Catalonia», en M. Asenjo González (ed.), Oligarchy and patronage in late medieval Spanish urban society, Turnhout, Brepols, pp. 1-27. 
SALES FAVÀ, Ll. (2011), «Crédito y redes urbanas: el caso de Girona y las pequeñas ciudades de su entorno en el siglo XIV», en D. Carvajal de la Vega et alii (eds), Redes sociales y económicas en el mundo bajomedieval, Valladolid, Castilla Ediciones, pp. 135-154

SÁNCHEZ DE MOVELLÁN TORENT, I. (2004), Les institucions fiscalitzadores de la Generalitat de Catalunya (Des de la reforma de 1413 fins al final del regnat de l'Emperador Carles I, el 1556), Barcelona, Sindicatura de Comptes de Catalunya. SÁNCHEZ MARTÍNEZ, M. (1999), «Fiscalidad y finanzas de una villa señorial catalana: Castelló d’Empúries, 1381-1382», en M. Sánchez (ed.), Fiscalidad real y finanzas urbanas en la Cataluña medieval, Barcelona, CSIC-IMF, pp. 301-362.

- ed. (2009), La deuda pública en la Cataluña bajomedieval, Barcelona, CSIC-IMF.

- y ORTI GOST, P. (1997a), «La Corona en la génesis del sistema fiscal municipal en Cataluña (1300-1360)», en Col-loqui Corona, municipis i fiscalitat a la Baixa Edat Mitjana, Actes, Lleida, pp. 233-278.

- (1997b), Corts, Parlaments $i$ fiscalitat a Catalunya: Els capítols del donatiu (1288-1384), Barcelona, Generalitat de Catalunya-Departament de Justícia.

- FURIÓ DIEGO, A., y SESMA MUÑOZ, J. A. (2008), «Old and New Forms of Taxation in the Crown of Aragon (13th-14th Centuries)», en S. Cavaciocchi (ed.), La fiscalità nell'economia europea secc. XIII-XVIII, Atti della «Trentanovesima Settimana di Studi», 22-26 aprile 2007, Firenze, Firenze University Press, vol. I, pp. 99-130.

SOBREQUÉS VIDAL, S. (1955), «Régimen municipal gerundense en la baja edad media. La "insaculación”», Anales del Instituto de Estudios Gerundenses, 10, pp. $165-232$.

TORRAS SERRA, M. (1999), «El deute públic a la ciutat de Manresa a la baixa edat mitjana», en M. Sánchez (ed.), Fiscalidad real y finanzas urbanas en la Cataluña medieval, Barcelona, CSIC-IMF, pp. 155-183.

TURULL RUBINAT, M. (1990), La configuració jurídica del municipi baix-medieval. Règim municipal i fiscalitat a Cervera entre 1182-1430, Barcelona, Fundació Noguera, pp. 426-427

VERDÉS PIJUAN, P. (1999), «Les finances del clavari: abast, límits i funcionament (Cervera, 1442)», Anuario de Estudios Medievales, 29, pp. 1134-1164.

- (2004), «Per ço que la vila no vage a perdició», La gestió de deute públic en un municipi català (Cervera, 1387-1516), Barcelona, CSIC-IMF. 
Albert Reixach Sala

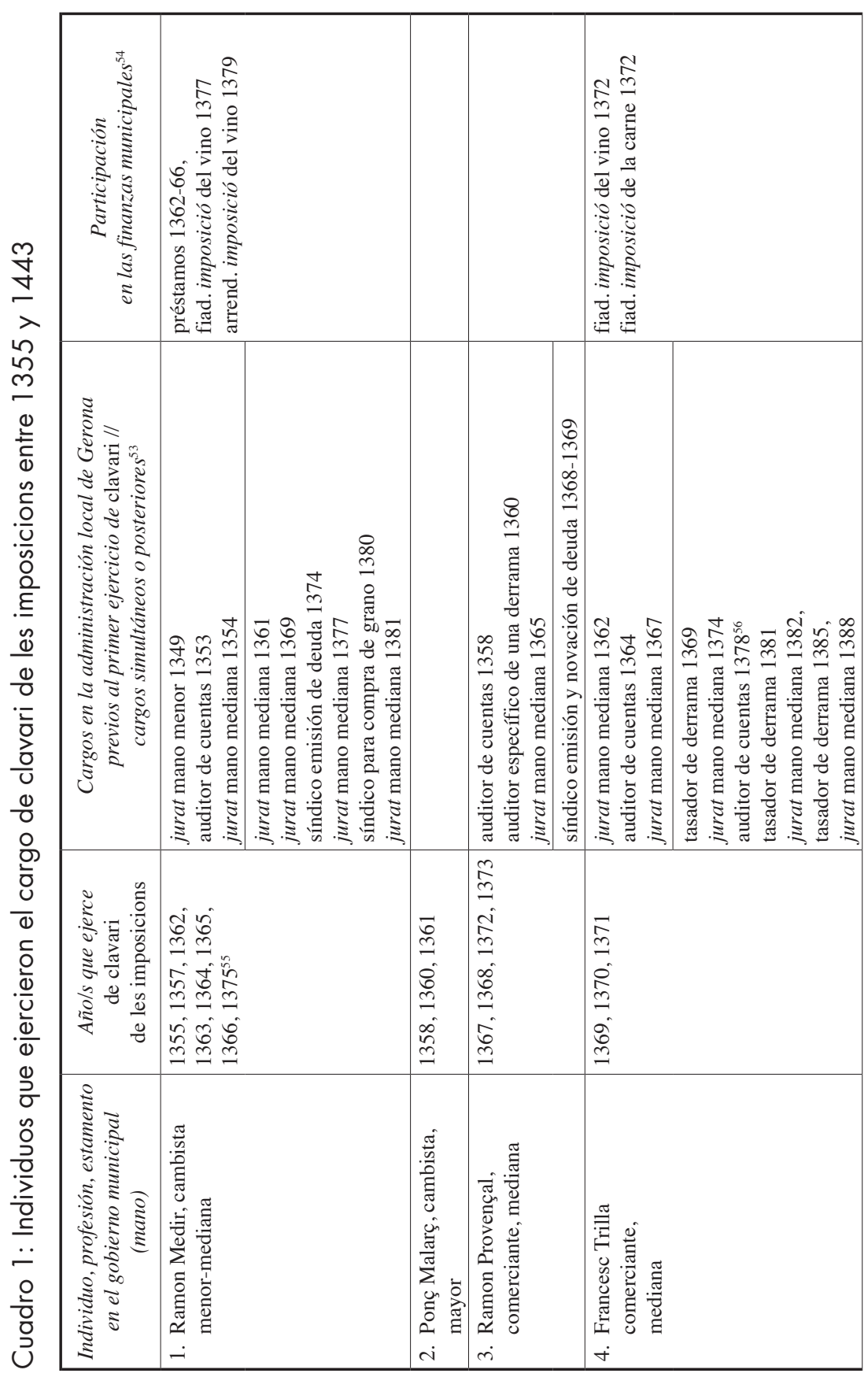


Hacienda local y redes financieras en la Cataluña bajomedieval...

\begin{tabular}{|c|c|c|c|c|c|}
\hline 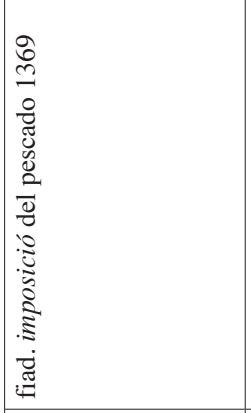 & 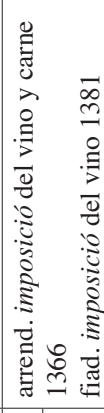 & & 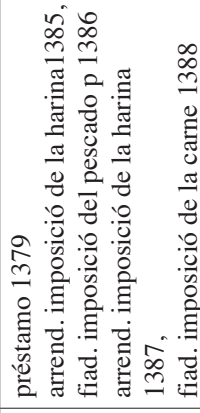 & 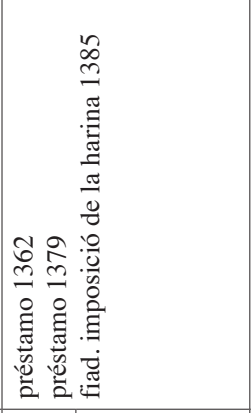 & 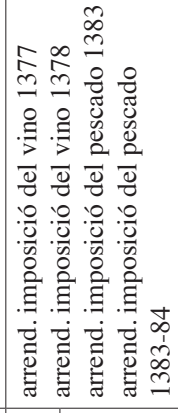 \\
\hline 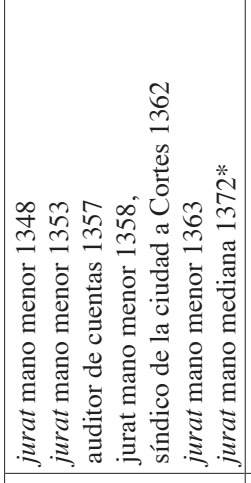 & 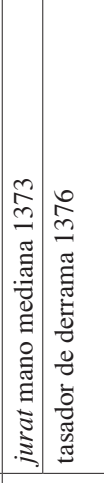 & 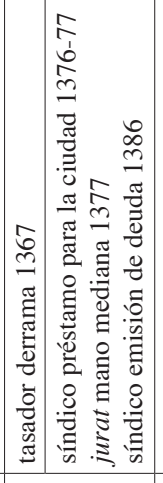 & 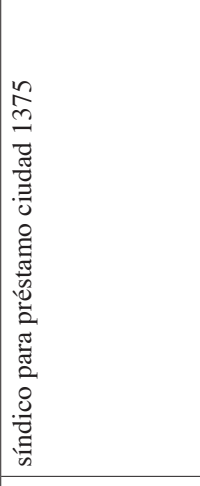 & 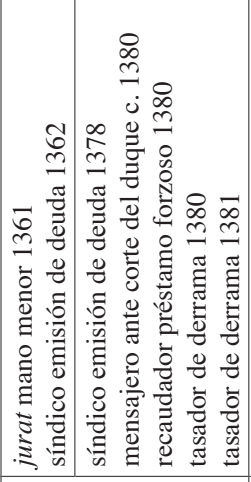 & 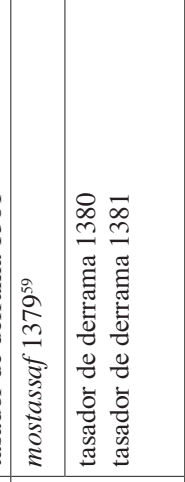 \\
\hline$\stackrel{+}{\stackrel{\Delta}{2}}$ & $\frac{d}{\Delta}$ & 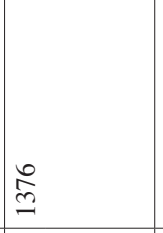 & 占 & $\frac{\infty}{2}$ & 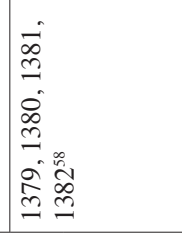 \\
\hline 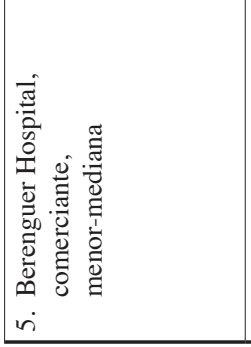 & 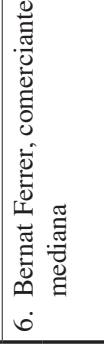 & 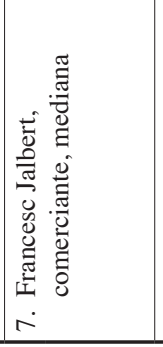 & 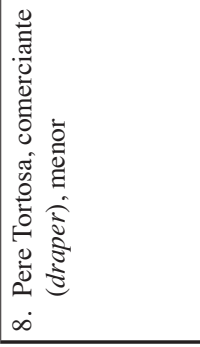 & 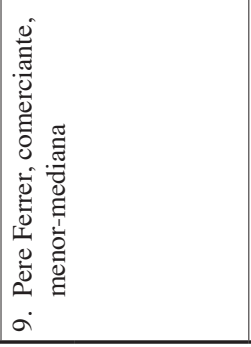 & 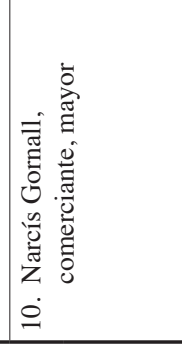 \\
\hline
\end{tabular}


Albert Reixach Sala

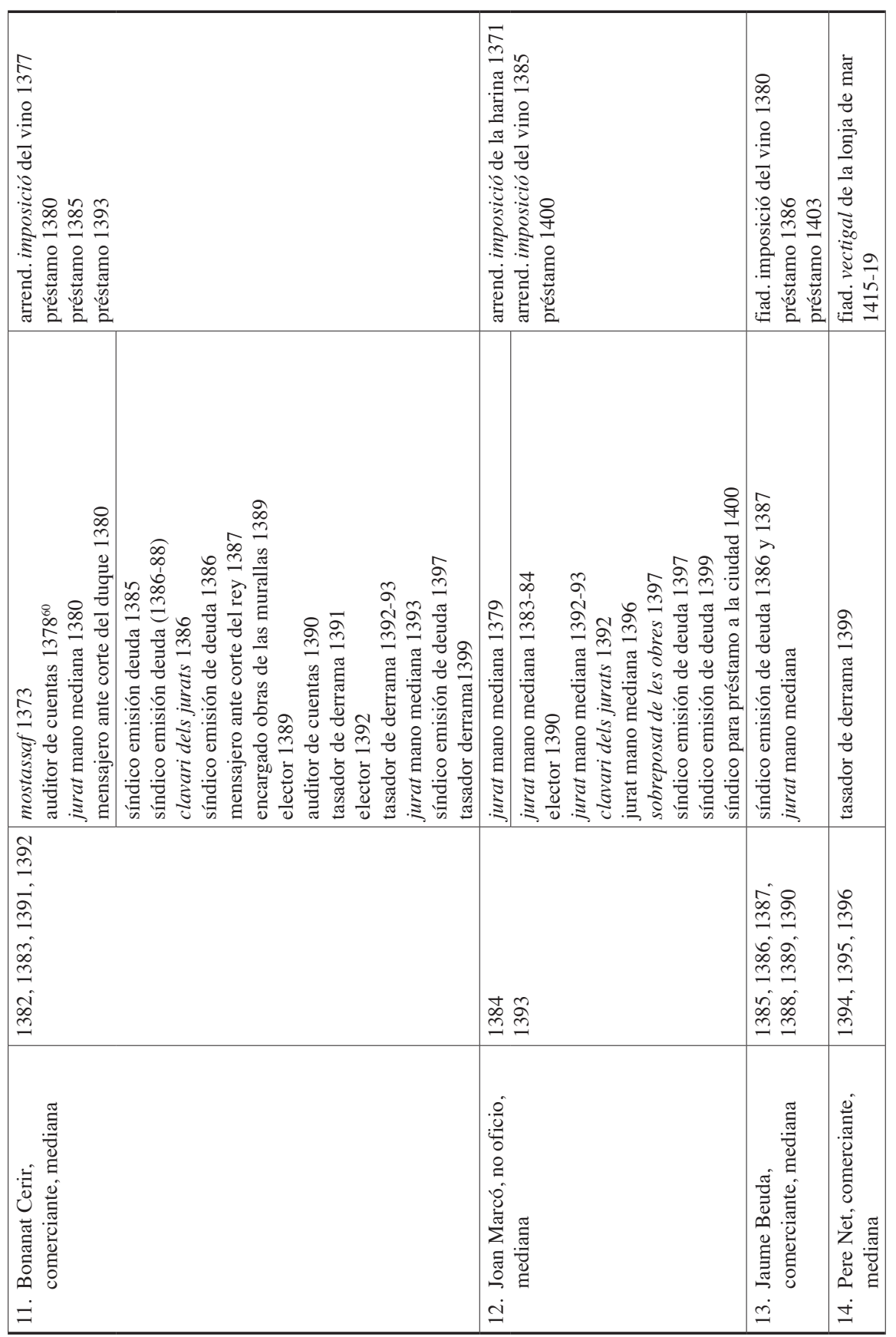


Hacienda local y redes financieras en la Cataluña bajomedieval...

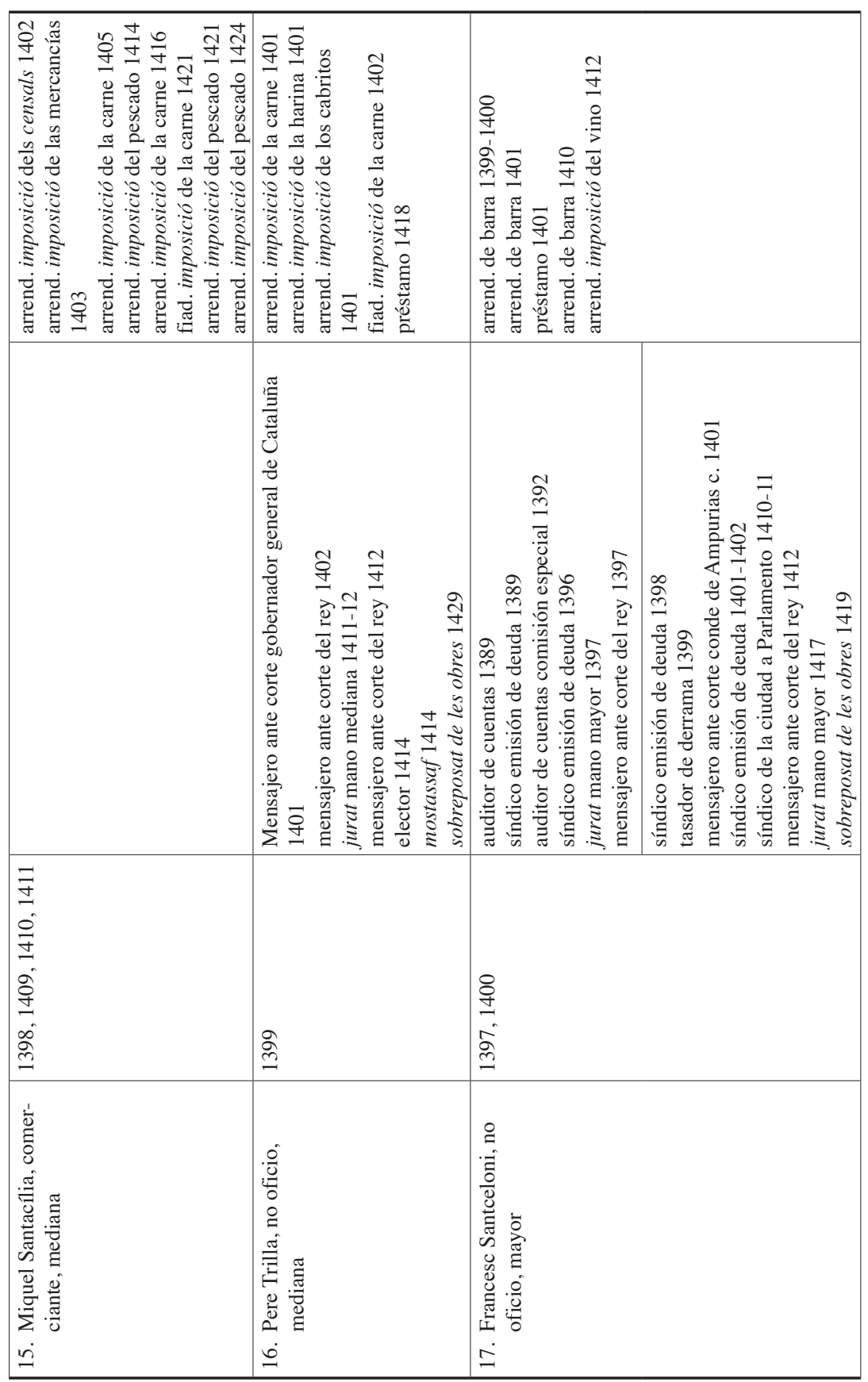


Albert Reixach Sala

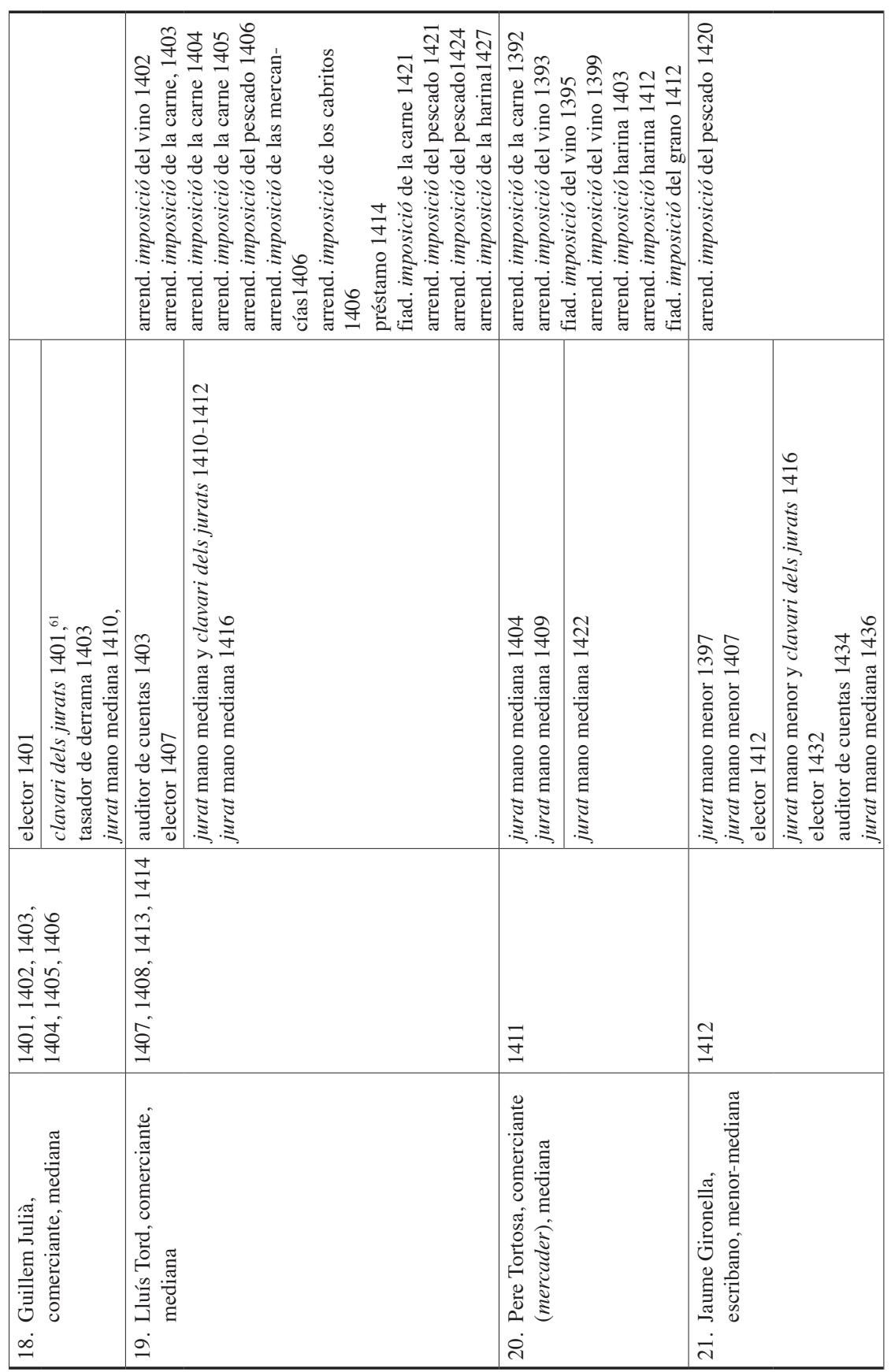


Hacienda local y redes financieras en la Cataluña bajomedieval...

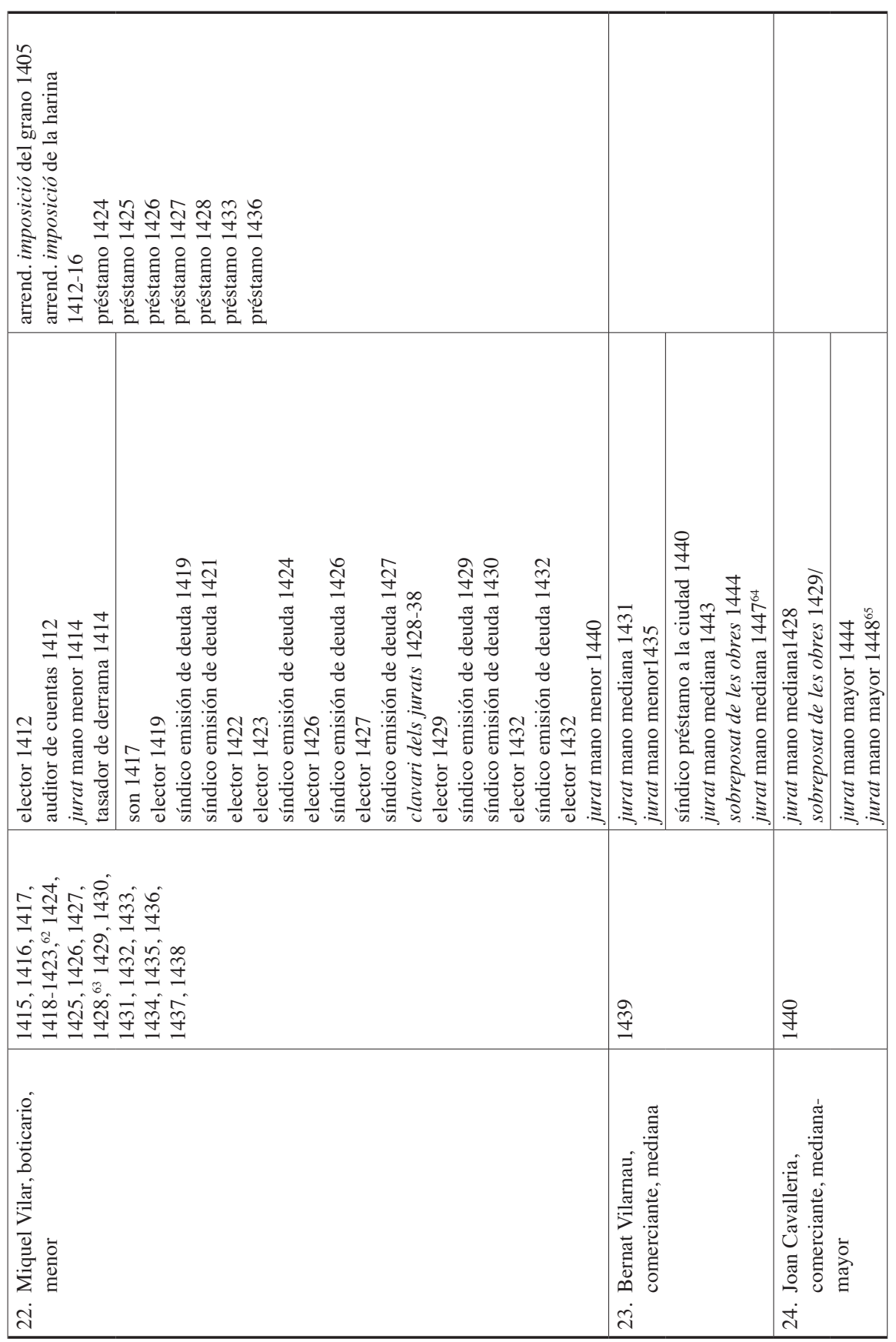


Albert Reixach Sala
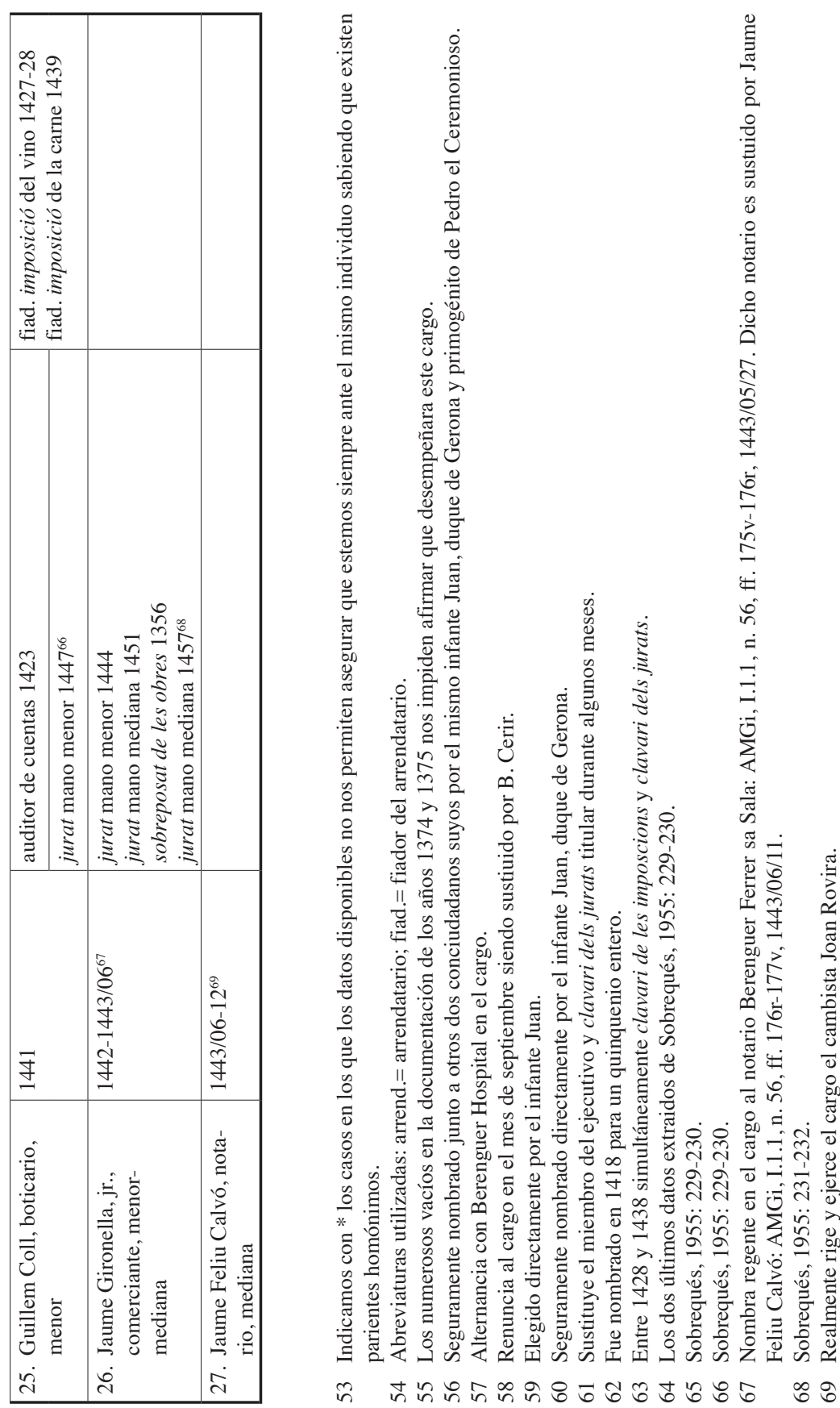